Check for updates

Cite this: Chem. Commun., 2021, 57,10139

Received 28th July 2021,

Accepted 9th September 2021

DOI: 10.1039/d1cc04100b

rsc.li/chemcomm

\section{Entering new chemical space with isolable complexes of single, zero-valent silicon and germanium atoms}

\author{
Shenglai Yao, (D) Yun Xiong, (D) Artemis Saddington and Matthias Driess (D)*
}

\begin{abstract}
Monatomic zero-valent silicon and germanium complexes (silylones and germylones), stabilised by neutral donating ligands, emerged only recently as a new class of low-valent group 14 element compounds. Featuring four valence electrons in the form of two lone pairs at a single site, silylones and germylones represent a molecular resting state of single Si and Ge atoms, which are typically only observed at high temperature in the gas phase or in interstellar matter. These species are capable of transferring single $\mathrm{Si}$ and $\mathrm{Ge}$ atoms to unsaturated substrates and acting as building blocks for novel group 14 species. After introducing this type of compound and the examples known to date, this feature article highlights some chelating bis $\mathrm{N}$-heterocyclic carbene (bis(NHC)) and bis $\mathrm{N}$-heterocyclic silylene (bis(NHSi)) supported $\mathrm{Si}^{0}$ and $\mathrm{Ge}^{0}$ complexes, for which a range of unprecedented reactivity has been discovered. The characteristic behaviour of these silylones and germylones discussed here consists of (i) coordination to Lewis acids, (ii) oxidation with elemental chalcogens, (iii) bond activation of common organic substrates and inert small molecules; and (iv) homocoupling of the $\mathrm{Si}^{0}$ and $\mathrm{Ge}^{0}$ centres. This wealth of reactivity has opened the door to a series of Si and Ge compounds, which would be otherwise difficult to realise.
\end{abstract}

\section{Introduction}

Our understanding of molecular complexes of single, zerovalent group 14 elements (ylidones, Chart 1) began following the calculations of Frenking and co-workers. They examined the donor-acceptor interactions in carbodiphosphorane $\mathrm{Ph}_{3} \mathrm{P} \rightarrow: \mathrm{C}: \leftarrow \mathrm{PPh}_{3}$ with quantum chemical analysis in $2006 .{ }^{1}$ The bonding situation between the carbon centre and both phosphorus atoms in $\mathrm{C}\left(\mathrm{PPh}_{3}\right)_{2}$, prepared already in 1961 by Ramirez, ${ }^{2,3}$ was previously described as containing electronsharing bonds (double Wittig ylide). However, a theoretical analysis of the frontier orbitals of $\mathrm{C}\left(\mathrm{PPh}_{3}\right)_{2}$ demonstrated the presence of a p-type lone pair orbital corresponding to the HOMO (Highest Occupied Molecular Orbital) and an s-type lone pair orbital as the HOMO-1, both located at the central carbon atom. ${ }^{1}$ As a result, $\mathrm{C}\left(\mathrm{PPh}_{3}\right)_{2}$ was reinterpreted as a single carbon atom complex due to the donor-acceptor interactions between two electron-donating phosphines and a "bare" carbon(0) atom, which retains its four valence electrons as two lone pairs. The term "carbones" was subsequently suggested by Frenking for such monatomic $\mathrm{C}^{0}$ complexes coordinated by Lewis

Department of Chemistry, Metalorganics and Inorganic Materials, Technische Universität Berlin, Strasse des 17. Juni 135, Sekr. C2, D-10623 Berlin, Germany. E-mail: matthias.driess@tu-berlin.de

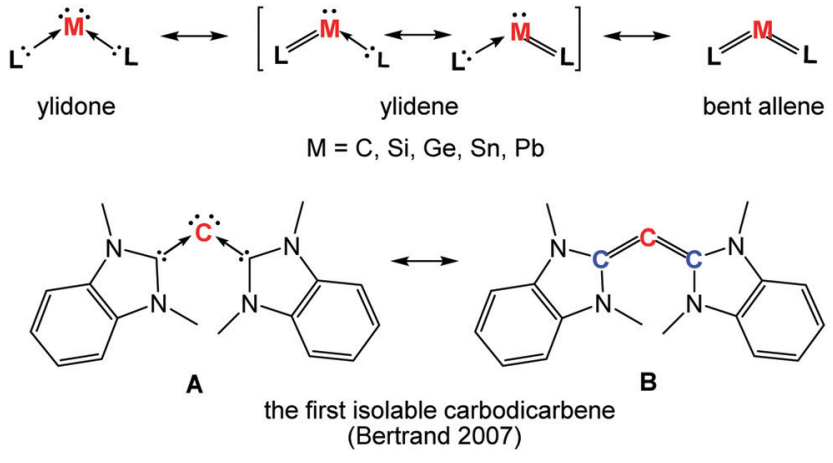

Chart 1 The general form of ylidone and its ylidene and bent allene forms, and the resonance structures $\mathbf{A}$ and $\mathbf{B}$ of the first isolable carbodicarbene.

donors. ${ }^{4,5}$ In addition, the terms silylone, germylone, stannylone, and plumbylone were suggested to label such complexes of the corresponding heavier group 14 elements in the zero oxidation state. $^{6}$ Carbones, featuring two lone pairs at the carbon centre, differ significantly electronically from carbenes with a singlet carbon centre in the +2 oxidation state. Such carbenes possess only one lone pair of electrons and one formally vacant orbital at the carbon centre, with the remaining two electrons involved in two electron-sharing bonds. ${ }^{7}$ In 2007, Tonner and Frenking 
predicted that carbodicarbenes $\mathrm{NHC} \rightarrow: \mathrm{C}: \leftarrow \mathrm{NHC}(\mathrm{NHC}=$ $\mathrm{N}$-heterocyclic carbene $)^{8}$ should be stable enough to be synthesised. ${ }^{9}$ They were in fact correct with the group of Bertrand reporting the synthesis of the first isolable carbodicarbene in 2008, which has two resonance forms as shown in Chart 1 (bottom). This carbodicarbene is able to coordinate to $\mathrm{RhCl}(\mathrm{CO})_{2}$ via the carbon(0) centre, demonstrating the predominance of the carbone resonance form $\mathbf{A}$, with active lone pairs at the carbon centre, over the bent allene $\mathbf{B} .^{10}$

Moving down group 14 to silicon and germanium, in 2003 heavy ylidones began to be explored following the investigations of Kira and co-workers, who reported the first trisilaallene $\mathbf{C}\left(\mathbf{M}^{\prime}=\mathrm{Si}\right.$, Chart 2). ${ }^{11-14}$ Similar to the above-mentioned case of carbodiphosphorane, a theoretical analysis of the bonding situation in related model compounds suggested that the $\mathrm{Si}=\mathrm{Si}$ bonding in $\mathbf{C}$ should also be reconsidered as donoracceptor interactions between the central silicon atom and two
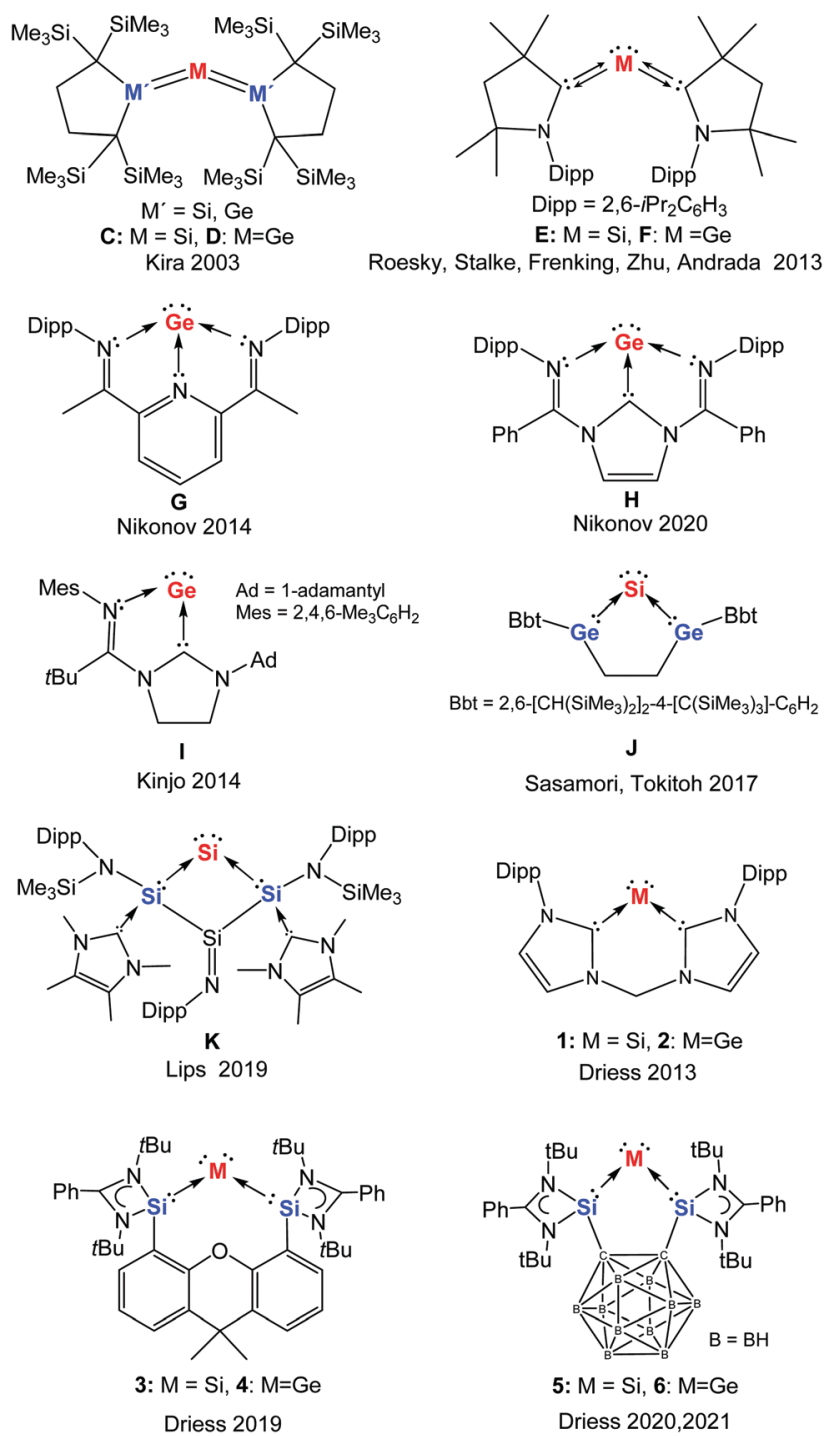

Chart 2 Known monatomic silicon(0) and germanium(0) complexes $\mathbf{C}-\mathbf{K}$ and 1-6. silylene ligands. ${ }^{15}$ Accordingly, the trisilaallene $\mathbf{C}\left(\mathbf{M}^{\prime}=\mathrm{Si}\right)$ was then described as a silylone and the 1,3-disilagermaallene $\mathbf{D}$ $\left(\mathrm{M}^{\prime}=\mathrm{Si}\right.$, Chart 2) ${ }^{16}$ as a germylone. In 2013, experimental realisation of the silylone $\mathbf{E}$ (also known as a siladicarbene, Chart 2) supported by two cyclic alkyl amino carbenes (cAACs) ${ }^{17}$ was achieved by Roesky, Stalke, and Frenking. ${ }^{18}$ In the same year, our group reported the first cyclic silylone $\mathbf{1}$ (Chart 2) with the central silicon atom coordinated by a neutral chelating bis(NHC) ligand, ${ }^{19}$ followed by the analogous germylone 2 (Chart 2, also known as germadicarbene) with the same bis(NHC) ligand. ${ }^{20}$ Meanwhile, the isolation of cAAC-supported acyclic germylone $\mathbf{F}$ (Chart 2) was achieved by Roesky, Zhu, Stalke, and Andrada, ${ }^{21}$ and subsequently the germanium(0) complexes $\mathbf{G},{ }^{22} \mathbf{H},{ }^{23}$ and $\mathbf{I}^{24}$ ligated by imino containing systems were obtained by Nikonov and Kinjo, respectively.

A deeper understanding of the bonding situation in heavy group 14 zero-valent complexes was probed by Turek et al. in 2017. By combining valence bond (VB) theory and maximum probability domain (MPD) approaches, they concluded that the bonding between the central group 14 atom and the donating ligands should be described as a resonating combination of "ylidone" and "ylidene" structures with a minor contribution of the "bent allene" structure (Chart 1 top). ${ }^{7}$ The stabilisation of silicon(0) and germanium(0) complexes with various silylene and germylene ligands was also investigated by Phukan and Gadre using density functional theory (DFT) and molecular electrostatic approaches. They concluded that such $\mathrm{Si}^{0}$ and $\mathrm{Ge}^{0}$ complexes contain very strong donor-acceptor bonds and are thermodynamically stable. ${ }^{25}$ In 2017 Sasamori and Tokitoh isolated the bent 1,3-digerma-2-silaallene $\mathbf{J}$ which could be better described as a germylene-coordinated $\mathrm{Si}^{0}$ compound with pronounced silylone character, rather than as a $=\mathrm{Ge}=\mathrm{Si}=\mathrm{Ge}=$ heterocumulene, due to the cyclic skeleton and the $\sigma$-donating properties of the germylene moieties. ${ }^{26}$ In addition, the group of Lips synthesised the bis-silylene stabilised silylone $\mathbf{K}^{27}$ Very recently, utilising the strongly donating bis(NHSi) (N-heterocyclic silylene) ligands we developed two new silylones $\left(3^{28}\right.$ and $\left.5^{29}\right)$ and two new germylones $\left(4^{30}\right.$ and $\left.6^{31}\right)$.

Akin to carbones, the central silicon and germanium atoms of silylones and germylones are in the zero oxidation state and retain their four valence electrons as two lone pairs. They represent a molecular resting state of single $\mathrm{Si}$ and Ge atoms, which are typically only observed at high temperature in the gas phase or in interstellar matter. ${ }^{32-34}$ This type of chemical species was proposed to represent a soluble "allotrope" of the respective elements. ${ }^{35}$ Owing to the peculiar bonding situation and high electron-richness of the central atoms, these complexes exhibit diverse reactivity with access to novel compounds. Cyclic ylidones developed in our group using bis(NHC) and bis(NHSi) ligands have allowed us to more widely explore the reactivity of genuine silylones and germylones, as well as enabling some comparison with already existing acyclic analogues. This feature article is focused on the chemistry of existing isolable monatomic silicon(0) and germanium(0) complexes, highlighting their synthesis, structure, and reactivity, with a particular focus on the cyclic bis(NHC) and bis(NHSi) supported silylones and 
germylones. Previous results of isolable zero-valent $\mathrm{Si}, \mathrm{Ge}$, and Sn were reviewed by Sasamori ${ }^{36}$ and our group. ${ }^{37}$ The dative bonding in zero-valent group 14 complexes has also been reviewed by Frenking and co-workers recently. ${ }^{38-40}$

\section{Synthesis of monatomic silicon(0) and germanium(0) complexes}

\subsection{Silylones and germylones $\mathrm{C}-\mathrm{K}$}

The first isolable silicon compound with silylone character to be reported (mentioned above) is the trisilaallene $\mathbf{C}$ (Chart 2, $\mathbf{M}^{\prime}=\mathrm{Si}$ ) obtained by Kira and co-workers in $2003 .^{11}$ It was synthesised from silicon tetrachloride and a cyclic dialkylsilylene ${ }^{41}$ in a two-step reaction, including reduction with potassium graphite. The molecular structure of $\mathbf{C}$ established by X-ray diffraction analysis (XRD) at $-150{ }^{\circ} \mathrm{C}$ revealed a significantly bent $\mathrm{Si}-\mathrm{Si}-\mathrm{Si}$ angle $\left[136.49(6)^{\circ}\right]$ and two relatively short $\mathrm{Si}-\mathrm{Si}$ bonds $[2.177(1) / 2.188(1) \AA]$. With a similar synthetic strategy, Kira and co-workers developed the first examples of 1,3-digermasilaallene $\mathbf{C}$ (Chart 2, $\left.\mathbf{M}^{\prime}=\mathrm{Ge}\right){ }^{42}$ 1,3-disilagermaallene $\mathbf{D}$ $\left(\mathbf{M}^{\prime}=\mathrm{Si}\right),{ }^{16}$ and trigermaallene $\mathbf{D}\left(\mathbf{M}^{\prime}=\mathrm{Ge}\right) .{ }^{42}$ It is of note that the related tristannaallene $\left(t \mathrm{Bu}_{3} \mathrm{Si}\right)_{4} \mathrm{Sn}_{3}$ was actually already reported by Wiberg and co-workers a few years earlier in 1999. ${ }^{43}$

The acyclic silylone (cAAC) ${ }_{2} \mathrm{Si} \mathbf{E}$ (Chart 2) was isolated by the groups of Roesky, Stalke, and Frenking in $2013 .^{18,44}$ The precursor of this silylone is a stable carbene-centred biradical (cAAC) $)_{2} \mathrm{SiCl}_{2}{ }^{45}$ resulting from the reaction of $\mathrm{SiCl}_{2}\left({ }^{\mathrm{D}} \mathrm{NHC}\right)^{46}$ $\left[{ }^{\mathrm{D}} \mathrm{NHC}=1,3\right.$-bis(Dipp)-imidazol-2-ylidene, $\operatorname{Dipp}=2,6$-diisopropylphenyl] and the free $\mathrm{CAAC}^{17}$ ligand. Reduction of the $\mathrm{Si}(\mathrm{Iv})$ species (cAAC) ${ }_{2} \mathrm{SiCl}_{2}$ with potassium graphite in THF furnished the silylone $\mathbf{E}$ in good yield. It was later revealed that this silylone can additionally be obtained from either the reaction of cAAC with $\mathrm{H}_{2} \mathrm{SiI}_{2}$ or the reduction of the $\mathrm{Si}$ (I) radical (cAAC) $)_{2}$ SiI with LiN(iPr $)_{2} \cdot{ }^{47}$ Although the silylone E features a silicon atom in the formal oxidation state zero, it exhibits remarkable stability. The amorphous powder of $\mathbf{E}$ is stable for an hour while its crystals are stable for about a day in air, according to the observed colour change. The germanium homologue (cAAC) ${ }_{2}$ Ge F (Chart 2) was isolated by Roesky, Zhu, Stalke, and Andrada through a one-pot synthesis with $\mathrm{GeCl}_{2}$ (dioxane), cAAC, and potassium graphite in a $1: 2: 2.1$ molar ratio. ${ }^{21}$ According to DFT calculations of (cAAC) $)_{2} \mathrm{Si}$ and (cAAC) ${ }_{2} \mathrm{Ge}$, the predominant contribution to the HOMO-1 is an s-type lone pair orbital and to the HOMO is a p-type orbital with largest extension at the central atoms, indicating their ylidone character. ${ }^{18,21}$ However, as a result of the highly $\pi$-accepting nature of the cAAC ligand, the ylidone character of $\mathbf{E}$ and $\mathbf{F}$ is considerably reduced, which accounts for the remarkable stability of silylone $\mathbf{E}$.

Utlising a tridentate bis(imino)pyridine ligand, which has also been employed for stabilising iron(0) complexes, ${ }^{48}$ Nikonov and co-workers were able to isolate the germanium(0) complex $\mathbf{G}$ (Chart 2). ${ }^{22}$ This three-coordinate germanium complex G was generated in moderate yield by the reduction of the bis(imino)pyridine $[\mathrm{GeCl}]^{+}$adduct resulting from autoionisation of germanium dichloride. Owing to the non-innocent character of the bis(imino)pyridine platform, this formal zerovalent germanium species possesses some multiple-bond character between the Ge atom and imine- $\mathrm{N}$ atoms as a result of delocalisation of one Ge lone pair into the $\pi^{*}(\mathrm{C}=\mathrm{N})$ orbitals. A related three-coordinate $\operatorname{tin}(0)$ complex, resulting from the transamination reaction of a bis(imino)pyridine ligand with $\mathrm{Sn}\left[\mathrm{N}\left(\mathrm{SiMe}_{3}\right)_{2}\right]_{2}$ in diethyl ether, was described by Fischer and Flock. ${ }^{49}$

Very recently, the group of Nikonov succeeded in the synthesis of the germanium $(0)$ complex $\mathbf{H}$, in which the germanium atom is stabilised by a tridentate diimino-NHC (dimNHC) ligand. ${ }^{23}$ In contrast to the bis(imino)pyridine-supported $\mathrm{Ge}^{0} \mathbf{G}$, complex $\mathbf{H}$ exhibits some interesting reactivity towards organic substrates with the involvement of the NHC-carbon(II) atom [C(II) oxidised to $\mathrm{C}(\mathrm{Iv})$, vide infra].

Starting from a related bidentate (mono)imino-NHC ligand system, Kinjo and co-workers prepared a chlorogermyliumylidene via autoionisation of germanium dichloride as a suitable precursor for the germanium(0) complex I (Chart 2). ${ }^{24}$ Reduction of this precursor with potassium graphite afforded the cyclic germanium complex I. DFT calculations revealed that one of the lone pairs of the central Ge atom significantly delocalises over the five-membered $\mathrm{C}_{2} \mathrm{~N}_{2} \mathrm{Ge}$ ring. Thus compound I may be viewed as both a germanium(0) species and a mesoionic germylene.

Sasamori and Tokitoh recently achieved the highly bent 1,3-digerma-2-silaallene $\mathbf{J}$ (mentioned previously, Chart 2). ${ }^{26}$ The (tetra)chlorinated precursor of $\mathbf{J}$ (1,1,2,5-tetrachloro-2,5digerma-1-sila-cyclopentane) was synthesised by heating the germanium-based ligand 1,2- $\mathrm{Bbt}_{2}-1,2$-digermacyclobutene ${ }^{50}$ $\left(\mathrm{Bbt}=2,6-\left[\mathrm{CH}\left(\mathrm{SiMe}_{3}\right)_{2}\right]_{2}-4-\left[\mathrm{C}\left(\mathrm{SiMe}_{3}\right)_{3}\right]-\mathrm{C}_{6} \mathrm{H}_{2}\right)$ in neat $\mathrm{SiCl}_{4}$. The subsequent reduction of this precursor with four molar equiv. of potassium graphite in benzene afforded $\mathbf{J}$ in moderate yield. Significantly enhanced silylone character has been assumed compared to that of acyclic trimetallallene such as $\mathbf{C}$ and $\mathbf{D}$, based on the relatively smaller Ge-Si-Ge angle $\left[80.08(4)^{\circ}\right]$.

Finally, Lips and co-workers described recently a carbeneinduced elimination of the tertiary amine $\operatorname{NDipp}\left(\mathrm{SiMe}_{3}\right)_{2}$, to afford the bicyclic amido- and carbene-substituted silicon ring compound $\mathbf{K}$ (Chart 2) with a $\mathrm{Si}=\mathrm{N}$ double bond and a twocoordinate $\mathrm{Si}$ atom. ${ }^{27}$ Spectroscopic investigations and DFT calculations of this bifunctional compound revealed significant silylone properties for the two-coordinate Si atom.

\subsection{Bis(NHC)-supported silylone 1 and germylone 2}

Since the beginning of last decade, we have been interested in developing silicon(0) and germanium(0) complexes with strongly sigma-donating and chelating ligands. Such compounds would allow us to realise a highly bent angle on the central $\mathrm{Si}^{0}$ and $\mathrm{Ge}^{0}$ atoms with enhanced reactivitiy, compared with non-chelating ligands and ligands featuring poorer sigma donors e.g. imines. Our first attempt was in 2012 with the isolation of the first chlorosilyliumylidene $[: \mathrm{SiCl}]^{+}$complex 7 with bis(tributylphosphazenyl)naphthalene as the chelating 


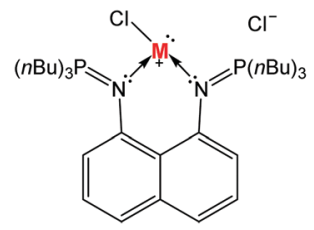

7: $\mathrm{M}=\mathrm{Si}, \mathbf{8}: \mathrm{M}=\mathrm{Ge}$

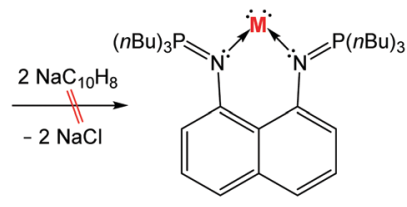

9: $M=S i, 10: M=G e$
Scheme 1 Reduction of chlorosilyliumylidene $\mathbf{7}$ and chlorogermyliumylidene $\mathbf{8}$ supported by bis(tributylphosphazenyl)naphthalene.

ligand (Scheme 1).${ }^{51}$ Compound 7 seemed to be a promising precursor for the hypothetic complex $\mathbf{9}$, however, its reduction with different reducing reagents such as potassium graphite and sodium naphthalenide led merely to unidentified mixtures of products. DFT calculations of 7 revealed that the lowest unoccupied molecular orbital (LUMO) was mainly localised on the naphthalene moiety of the supporting ligand, implying that the naphthalene backbone would be reduced over the silicon(II) centre. The same is true for our first attempt to prepare germanium(0) complex 10, starting from the corresponding bis(tributylphosphazenyl)naphthalene-ligated chlorogermyliumylidene [:GeCl $]^{+} \mathbf{8}$ with its LUMO localised also on the supporting ligand (Scheme 1). ${ }^{52}$

Considering the fact that NHCs have been employed for stabilising the diatomic silicon $(0)^{53}$ and germanium $(0)^{54} \mathrm{com}-$ plexes in the form of $\left({ }^{\mathrm{D} H C}\right): \mathrm{M}=\mathrm{M}:\left({ }^{\mathrm{D}} \mathrm{NHC}\right)(\mathrm{M}=\mathrm{Si}, \mathrm{Ge})$, we envisioned that a chelating bis(NHC) might be capable of supporting a monatomic silicon(0) or germanium(0) species. Starting with this bidentate bis(NHC), ${ }^{55}$ a ligand exchange reaction with $\operatorname{SiCl}_{2}\left({ }^{\mathrm{D} N H C}\right)^{46}$ in THF afforded the expected chlorosilyliumylidene $[: \mathrm{SiCl}]^{+}$complex 11 (Scheme 2$) .{ }^{19}$ As intended, both the HOMO and LUMO of $\mathbf{1 1}$ are mainly localised on the Si centre. A similar synthetic approach resulted in isolation of the analogous complex, bis(NHC)-ligated chlorogermyliumylidene 12 (Scheme 2). ${ }^{20}$ The HOMO and LUMO of this germanium(II) compound are also mainly located on the Ge(II) atom. With $\mathbf{1 1}$ and $\mathbf{1 2}$ as long-sought precursors for the corresponding zero-valent complexes in hand, we conducted their dechlorination with two molar equiv. of sodium

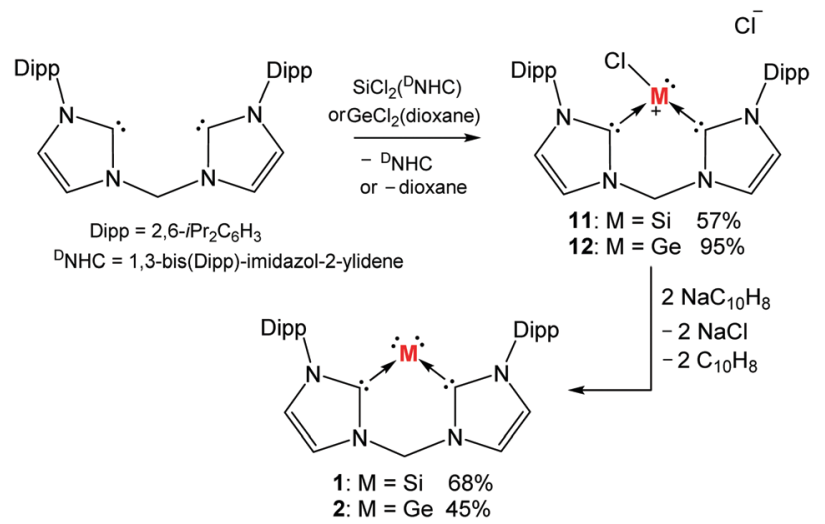

Scheme 2 Synthesis of the bis(NHC)-supported silylone 1 and germylone 2 via chlorosilyliumylidene 11 and chlorogermyliumylidene 12, respectively, starting from the bis( $\mathrm{NHC})$ ligand. naphthalenide. Indeed, the reduction of $\mathbf{1 1}$ in THF at $-60{ }^{\circ} \mathrm{C}$ furnished the desired silylone $\mathbf{1}$ which was isolated as a dark red powder (Scheme 2). ${ }^{19}$

The molecular structure of silylone 1 established by XRD (Fig. 1) reveals two $\mathrm{Si}-\mathrm{C}$ distances (av. $1.869 \AA$ A), both slightly longer than those observed for the acyclic silylone (cAAC) ${ }_{2} \mathrm{Si}$ $[1.841(2) \AA]$ reported by Roesky, Stalke, and Frenking, ${ }^{18}$ in which the cAACs act as much stronger $\pi$ electron acceptors than NHCs. Consequently, the $\mathrm{Si}^{0}$ centre of $\mathbf{1}$ is more electronrich than that in (cAAC) $)_{2} \mathrm{Si}$ as shown by the drastic upfield shift of the ${ }^{29} \mathrm{Si}$ NMR resonance [1: $\delta=-80.1 \mathrm{ppm} v s . \delta=66.7 \mathrm{ppm}$ for $\left.(\mathrm{cAAC})_{2} \mathrm{Si}\right]$. Moreover, silylone 1 shows larger first and second proton affinities $\left[\mathrm{PA}(1)=283.4, \operatorname{PA}(2)=168.3 \mathrm{kcal} \mathrm{mol}^{-1}\right]$ in comparison to those of (cAAC) $)_{2} \mathrm{Si}\left(268.8,155.3 \mathrm{kcal} \mathrm{mol}^{-1}\right)$ as suggested by DFT calculations based on molecular models. ${ }^{19}$ In line with these calculations, two lone pairs of electrons are confirmed at the silicon centre of silylone 1. The HOMO involves a silicon $\pi$-orbital with small degree of $\mathrm{Si}-\mathrm{C} \pi$ bonding and the HOMO-1 corresponds to a silicon $\sigma$-lone pair orbital. Notably, silylone 1 shows a deep-red colour in toluene and an absorption maximum at $\lambda=547 \mathrm{~nm}\left(\varepsilon=7.5 \times 10^{3}\right)$ was observed in the UV-vis spectrum.

As expected, the reduction of the bis(NHC)-supported chlorogermyliumylidene [: $\mathrm{GeCl}]^{+} \mathbf{1 2}$ with two molar equiv. of sodium naphthalenide in THF at $-30{ }^{\circ} \mathrm{C}$ furnishes the germylone 2 as a dark red powder (Scheme 2). ${ }^{20}$ The molecular structure established by XRD is isostructural with that of the silicon analogue 1 (Fig. 1). The two Ge-C distances of 1.967(2) and 1.962(2) $\AA$ in 2 are slightly longer than those in the acyclic $(\mathrm{cAAC})_{2} \mathrm{Ge}$ complexes [1.9386(16)-1.954(2) $\AA$ ] described by Roesky, Zhu, Stalke, and Andrada, ${ }^{21}$ indicating again the stronger electron accepting effect of cAACs $v s$. NHCs as supporting ligands. As suggested by the DFT calculations, the HOMO of 2 corresponds to a $\pi$-type orbital located at the Ge centre with appreciable $\mathrm{Ge}-\mathrm{C} \pi$ bonding character, while the HOMO-1 involves a $\sigma$ lone pair orbital at the Ge centre. ${ }^{20}$ The proton affinities of compound $2\left[\mathrm{PA}(1)=279.6, \mathrm{PA}(2)=175.0 \mathrm{kcal} \mathrm{mol}^{-1}\right]$ confirm the presence of two lone pairs at the germanium $(0)$ centre.

\subsection{Bis(NHSi)-ligated silylones and germylones 3-6}

Silylenes are divalent silicon species with two valence electrons as a lone pair and a formally empty orbital at the silicon centre. ${ }^{56-59}$

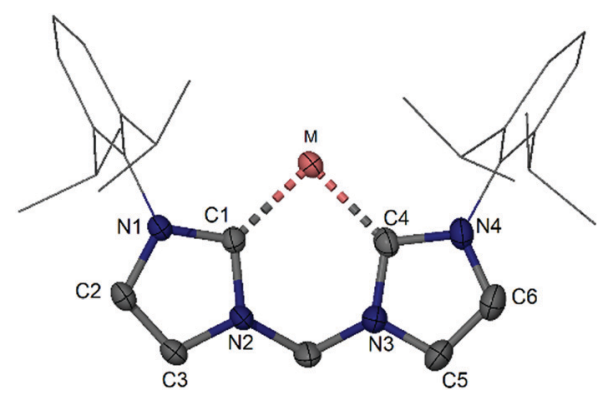

Fig. 1 Molecular structures of the bis(NHC)-supported silylone $1(\mathrm{M}=\mathrm{Si})$ and germylone 2 ( $M=G e$ ) (hydrogen atoms are omitted for clarity). 
Three-coordinate amidinato silylenes, $\mathrm{PhC}(\mathrm{N} t \mathrm{Bu})_{2} \mathrm{SiR}(\mathrm{R}=$ organic substituent), derived from $\left[\mathrm{PhC}(\mathrm{N} t \mathrm{Bu})_{2} \mathrm{SiCl}\right],{ }^{60}$ can serve as strong donating ligands in coordination chemistry due to the intramolecular electron donation of an imino moiety to the silylene centre. For instance, a digermanium(0) complex stabilised by the tricoordinate silylene $\left[\mathrm{PhC}(\mathrm{N} t \mathrm{Bu})_{2}\right] \mathrm{Si}\left(\mathrm{N}\left(\mathrm{SiMe}_{3}\right)_{2}\right)$ was reported by So and co-workers. ${ }^{61}$ Based on this type of NHSis, we recently developed several chelating bis(NHSi) systems and successfully applied them in transition metal coordination and catalysis. ${ }^{62-65}$ As the latter NHSis are generally stronger Lewis donors with respect to NHCs, ${ }^{66}$ we realised that such chelating NHSi ligands could also be applied for synthesising more reactive silylones and germylones. Starting with the pincer-type tridentate bis(NHSi)pyridine $13,{ }^{67}$ we synthesised the germanium(II) complex 14 as a precursor for a bis(NHSi) supported germylone (Scheme 3). While attempts for bis(NHSi)pyridine-Ge ${ }^{0}$ complex 15 via reductive dechlorination of $\mathbf{1 4}$ failed, the reaction with $\mathrm{K}_{2} \mathrm{Fe}(\mathrm{CO})_{4}$ resulted in the isolation of $\mathbf{1 6}$ as an iron(0) complex of the desired bis(NHSi)pyridene-Ge ${ }^{0}$ species, whereby the $\mathrm{Fe}(\mathrm{CO})_{4}$ moiety acts as a Lewis acid to stabilise one of the germylone lone pairs. The molecular structure of $\mathbf{1 6}$ shows a three-coordinate germanium atom bearing an $\mathrm{Fe}(\mathrm{CO})_{4}$ moiety in addition to two NHSis, adopting a trigonal-pyramidal geometry with a lone pair of electrons occupying the apex. Interestingly, insertion of $\mathrm{GeCl}_{2}$ into the $\mathrm{Ge} \rightarrow$ Fe donor-acceptor bond of 16 occurred when 16 was reacted with $\mathrm{GeCl}_{2}$ (dioxane), furnishing complex 17 (Scheme 3).

Considering that the failure to achieve the bis(NHSi)supported germylone $\mathbf{1 5}$ may be owing to the flexibility of the bis(NHSi)pyridine ligand, we selected the rigid bis(NHSi) $\mathbf{1 8}^{68}$
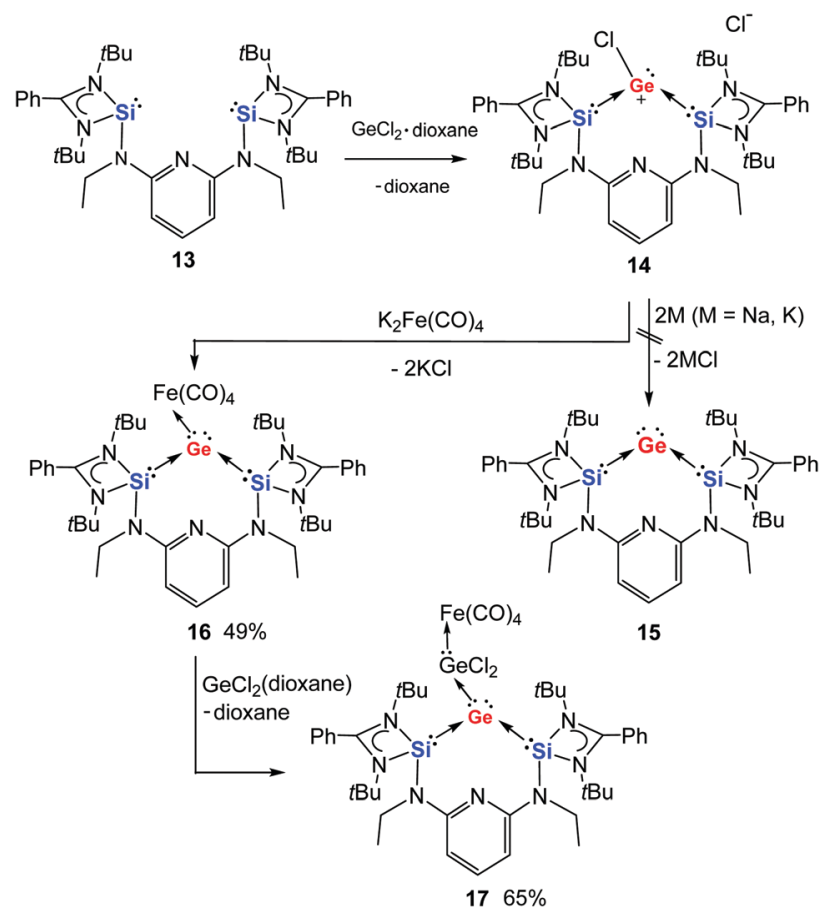

Scheme 3 Attempt to synthesise the bis(NHSi) supported germylone 15 via chlorogermyliumylidene 14, starting from bis(NHSi) 13, and the formation of 16 and 17 , respectively. with a xanthene scaffold in order to synthesise a bis(NHSi)supported silylone and germylone (Scheme 4). Dropwise addition of one molar equiv. of $\operatorname{SiCl}_{2}\left({ }^{\mathrm{D}} \mathrm{NHC}\right)^{46}$ in diethyl ether into a solution of $\mathbf{1 8}$ at room temperature leads to the formation of chlorosilyliumylidene chloride 19 as a yellow precipitate. ${ }^{28}$ It is of note that further reaction of $\mathbf{1 9}$ with one additional molar equiv. of $\mathrm{SiCl}_{2}\left({ }^{\mathrm{D}} \mathrm{NHC}\right)$ can occur via the insertion of : $\mathrm{SiCl}_{2}$ into the $\mathrm{Si}-\mathrm{Cl}$ bond of 19, affording the chlorosilane complex 20.

Starting from 19, reduction with two molar equiv. of potassium graphite in THF at ambient temperature affords a dark purple solution, from which the desired bis(NHSi)-supported silylone 3 is isolated as dark purple crystals (Scheme 4). ${ }^{28}$ Compound 3 is considerably sensitive towards air and moisture. Its ${ }^{29} \mathrm{Si}$ NMR spectrum exhibits a resonance at $\delta-187.5 \mathrm{ppm}$ in $\mathrm{C}_{6} \mathrm{D}_{6}$ assignable to the silicon(0) atom. This signal is significantly upfield shifted with respect to that of the bis(NHC)-supported silylone $1\left(\delta-80.1 \mathrm{ppm}\right.$ in $\left.\mathrm{C}_{6} \mathrm{D}_{6}\right)$, indicating the stronger $\sigma$-donating nature of the NHSi-Si(II) atoms.

In the crystal structure, two independent molecules of 3 with nearly identical geometric parameters are present in the asymmetric unit (Fig. 2). ${ }^{28}$ The $\mathrm{Si}-\mathrm{Si}$ bond distances of 3 ranging from $2.2451(7)$ to $2.2586(7) \AA$ are substantially longer than the analogous $\mathrm{Si}-\mathrm{Si}$ distances observed in trisilaallene $\mathbf{C}$ (Chart 2, $\mathrm{M}^{\prime}=\mathrm{Si}$ ) [2.177(1) and 2.188(1) Å] with two cyclic alkyl silylenes, ${ }^{11}$ implying the weaker $\pi$-accepting properties of an NHSi compared to that in a cyclic alkyl silylene. The $\mathrm{Si}-\mathrm{Si}-\mathrm{Si}$ bond angles $\left[104.38(3)^{\circ}\right.$ and $\left.103.87(3)^{\circ}\right]$ in the two independent molecules of 3 are considerably narrower than that in trisilaallene $\mathbf{C}\left(\right.$ Chart $\left.2 \mathbf{M}^{\prime}=\mathrm{Si}\right)\left[136.49(6)^{\circ}\right] .{ }^{11}$ The electronic structure of silylone 3 has been investigated by DFT calculations and Natural Bond Orbital (NBO) analysis, which revealed the presence of two perpendicular lone-pairs of electrons on the central silicon(0) atom, i.e., an $\mathrm{sp}^{0.41}$-type lone-pair and a delocalised $\mathrm{p}$ lone-pair. ${ }^{28}$ Despite the longer $\mathrm{Si}-\mathrm{Si}$ distances mentioned above, the Wiberg Bond Index (WBI) of the $\mathrm{Si}-\mathrm{Si}$

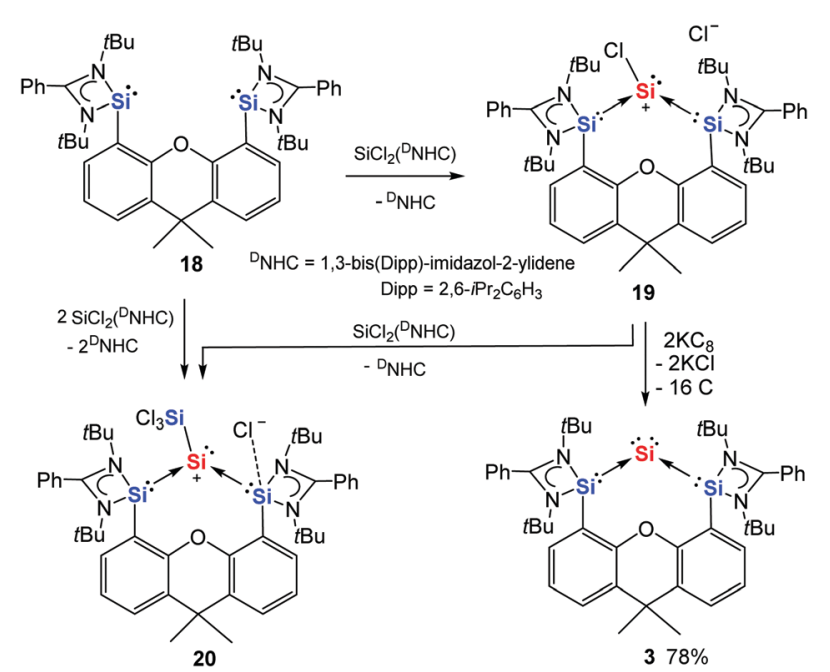

Scheme 4 Reaction of the bis(NHSi)xanthene 18 with $\mathrm{SiCl}_{2}\left({ }^{\mathrm{D}} \mathrm{NHC}\right)$ to afford the silicon(॥) chloride complexes 19 and 20 as well as the synthesis of bis(NHSi)-supported silylone 3 from 19 


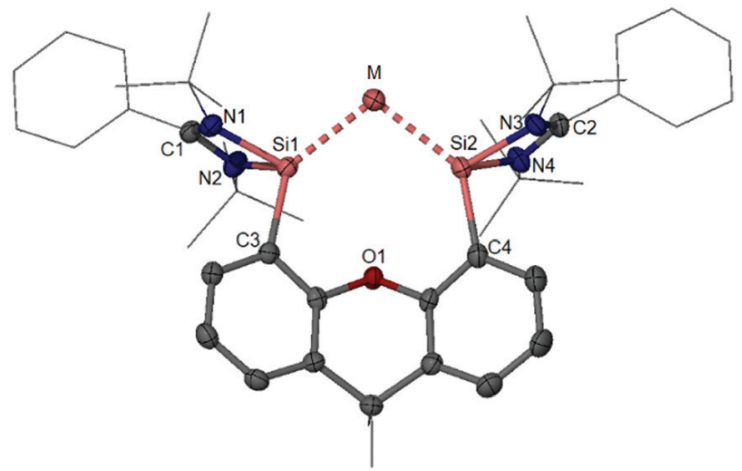

Fig. 2 Molecular structures of the xanthene-based bis(NHSi)-supported silylone $\mathbf{3}(\mathrm{M}=\mathrm{Si})$ and germylone $\mathbf{4}(\mathrm{M}=\mathrm{Ge})$ (hydrogen atoms are omitted for clarity).

bonds in 3 is 1.40 , indicating there is still some double bond character to the $\mathrm{Si}-\mathrm{Si}$ bonds.

Akin to the silicon analogue 19, the chlorogermyliumylidene chloride 21 supported by (bis-NHSi)xanthene can be prepared by treatment of the bis(NHSi) ligand $\mathbf{1 8}$ with one molar equiv. of $\mathrm{GeCl}_{2}$ (dioxane) in diethyl ether at room temperature (Scheme 5). ${ }^{30}$ In contrast to the silicon analogue, no further reaction of 21 with $\mathrm{GeCl}_{2}$ (dioxane) was observed, which makes the synthesis of $\mathbf{2 1}$ easier. Dechlorination of $\mathbf{2 1}$ with two molar equiv. of potassium graphite in THF at room temperature furnishes the desired bis(NHSi)-supported germylone $\mathbf{4}$ as dark blue crystals (Scheme 5). In the molecular structure of $\mathbf{4}$, established by XRD (Fig. 2), the Ge-Si distances of 2.3147(9) and 2.3190(9) $\AA$ are considerably longer with respect to those in 2-germadisilaallene $\mathbf{D}$ [Chart 2, $\mathrm{M}^{\prime}=\mathrm{Si}, 2.2366(7)$ and 2.2373(7) $\left.\mathrm{A}\right]$ again due to the weaker $\pi$-accepting ability of the NHSis compared to the cyclic alkyl silylenes. Moreover, the $\mathrm{Si}-\mathrm{Ge}-\mathrm{Si}$ angle $\left[102.87(3)^{\circ}\right]$ of $\mathbf{4}$ is much more acute than that of $\mathbf{D}$ $\left[132.38(2)^{\circ}\right]$. The calculated WBI of the Si-Ge bonds in 4 is 1.34, indicating a partial double bond character. ${ }^{30}$ Similar to the silicon analogue 3, the computational analysis suggests that germylone 4 features a $\mathrm{Ge}^{0}$ atom with two perpendicular lone

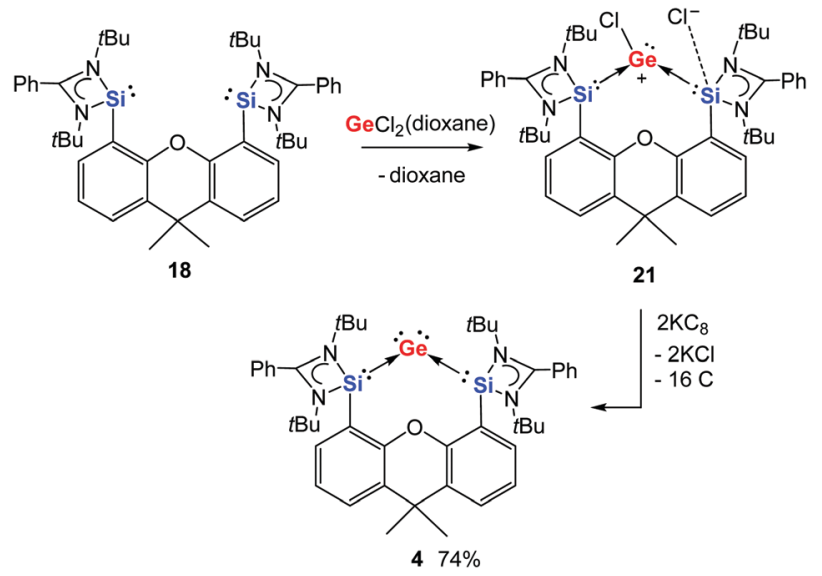

Scheme 5 Synthesis of bis(NHSi)xanthene-supported germylone $\mathbf{4}$ from $\mathbf{1 8}$ via the chlorogermyliumylidene $\mathbf{2 1}$.

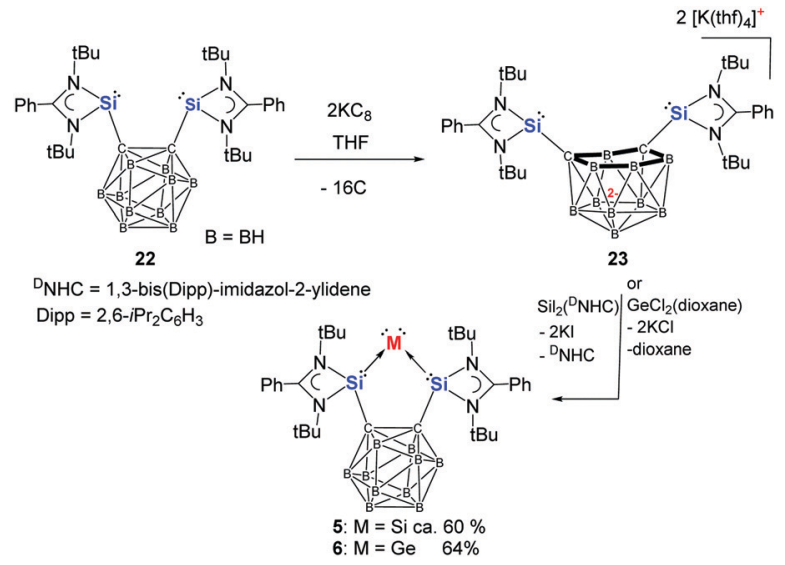

Scheme 6 Synthesis of the (bis-NHSi)carborane supported silicon(0) (5) and germanium (6) complexes from bis(NHSi) ligand 22 via the bis(NHSi) dianion 23

pairs, with some electron delocalisation into both silicon(II) formally vacant orbitals.

To realise a silylone and a germylone with an even more rigid bis(NHSi) ligand, we recently paid our attention to the bis(NHSi)-o-carborane $\mathbf{2 2}^{69}$ (Scheme 6) with a Si ‥Si distance of $c a$. $3.3 \AA$ documented by our group in 2016. Notably, $o$-carboranes can easily undergo cluster core opening via twoelectron reduction with alkaline metals to form nido-carborane dianions. ${ }^{70,71}$ Accordingly, the reaction of 22 with two molar equiv. of potassium graphite leads expectedly to the desired dipotassium 1,2-bis(silylenyl)-nido-carborane salt 23. Compound 23 undergoes a metathesis reaction with $\mathrm{SiCl}_{2}\left({ }^{\mathrm{D}} \mathrm{NHC}\right)^{46}$ or better $\mathrm{SiI}_{2}\left({ }^{\mathrm{D} N H C}\right)^{72}$ in THF to afford the bis(NHSi)-supported silylone $\mathbf{5}$ as a red powder. ${ }^{29}$

In the ${ }^{29} \mathrm{Si}\left\{{ }^{1} \mathrm{H}\right\}$ NMR spectrum of 5 , the signal of the central $\mathrm{Si}^{0}$ atom was observed at $\delta-263.8 \mathrm{ppm}$, which is even more strongly shielded by $76 \mathrm{ppm}$ compared to that of NHSisupported silylone $3(\delta-187.5 \mathrm{ppm}) .{ }^{29}$ The molecular structure of 5 has a $C_{2 \mathrm{v}}$ symmetry with a planar five-membered $\mathrm{C}_{2} \mathrm{Si}_{3}$ ring with two Si-Si distances of [2.2272(6) and 2.2225(6) $\AA]$ (Fig. 3), which are comparable to those observed for 3 [2.2451(7)$2.2586(7) \AA]$. Remarkably, silylone 5 exhibits a very narrow $\mathrm{Si}-\mathrm{Si}-\mathrm{Si}$ angle $\left[82.75(2)^{\circ}\right]$ relative to that in $3\left(104^{\circ}\right) .{ }^{28}$ According to quantum chemical calculations, the HOMO and the

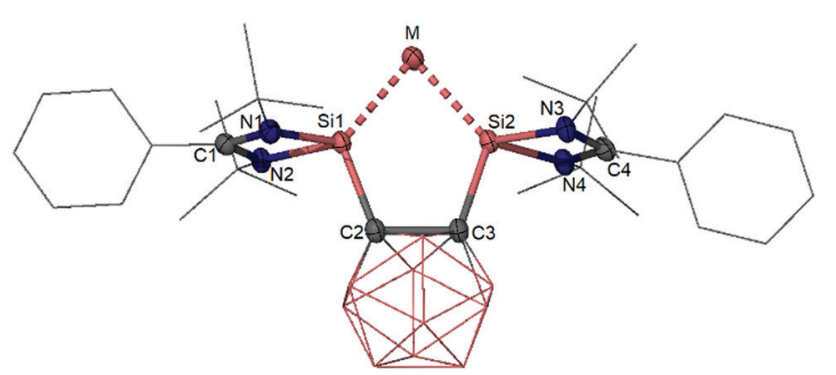

Fig. 3 Molecular structures of the o-caborane-based bis(NHSi) supported silylone $5(M=\mathrm{Si})$ and germylone $6(\mathrm{M}=\mathrm{Ge})$ (hydrogen atoms are omitted for clarity). 
HOMO-1 of 5 correspond to the silylone $\pi$ - and $\sigma$-symmetry lone pairs, respectively, resembling the situations of silylones $\mathbf{1}^{19}$ and $3 .^{28}$

Treatment of the nido-carborane dianions 23 with one molar equiv. of $\mathrm{GeCl}_{2}$ (dioxane) at room temperature in THF resulted in formation of the carborane-based germylone 6 which is isolated as a brown-red powder (Scheme 6). ${ }^{31}$ Germylone 6 is isostructural with its silicon analogue 5 (Fig. 3) with Ge-Si distances [2.2896(5) and 2.2846(5) $\mathrm{\AA}]$ close to those observed for the xanthene-based germylone 4 [2.3147(9) and 2.23190(9) $\mathrm{A} .^{30}$ However, the $\mathrm{Si}-\mathrm{Ge}-\mathrm{Si}$ angle of $80.59(2)^{\circ}$ in 6 is much more acute with respect to that in the xanthene-based germylone 4 $\left[102.87(3)^{\circ}\right]^{30}$ and even smaller than that of bis(NHC)-supported germylone $2\left[86.6(1)^{\circ}\right] .{ }^{20}$ As a genuine germylone, the HOMO and the HOMO-1 of 6 correspond to the germylone lone pairs with $\pi$ - and $\sigma$-symmetry respectively. ${ }^{31}$

\section{Reactivity of monatomic silicon(0) and germanium(0) complexes}

\subsection{Acting as a Lewis base}

Since silylones and germylones feature two lone pairs of electrons at the central silicon and germanium atoms, they are expected to act as Lewis bases to form stable donoracceptor adducts with appropriate Lewis acids. This was first proven by the reaction of silylone 1 with one molar equiv. of $\mathrm{GaCl}_{3}$ in THF, affording the silylone- $\mathrm{GaCl}_{3}$ complex 24 as a yellow solid (Scheme 7). ${ }^{73}$ The molecular structure of $\mathbf{2 4}$ exhibits a three-coordinate silicon atom adopting a pseudotetrahedral coordination geometry with a lone pair of electrons at the vertex position (Fig. 4). This suggests that one of the lone pairs at the silicon centre is donated to the $\mathrm{GaCl}_{3}$ moiety.

By analogy, coordination of 2 with $\mathrm{GaCl}_{3}$ yields the germanium complex 25 as a yellow solid (Scheme 7). ${ }^{74}$ Compound 25 is isostructural to its silicon analogue $\mathbf{2 4}$ and possesses also a lone pair on the germanium centre. It is worth mentioning that coordination of the germanium compound I (Chart 2) with $\mathrm{M}(\mathrm{CO})_{5}(\mathrm{M}=\mathrm{Cr}, \mathrm{Mo}, \mathrm{W})$ leads also to $1: 1$ adducts. $^{75}$ As shown by Kinjo and co-workers, however, the germanium centres

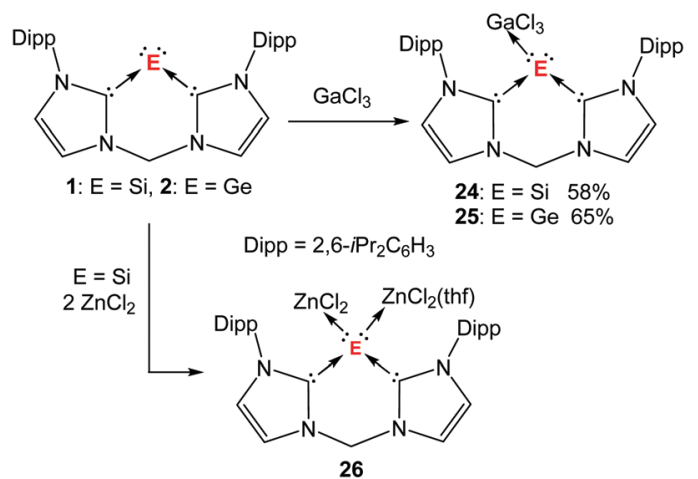

Scheme 7 Formation of $\mathrm{GaCl}_{3}$ adducts of bis(NHC)-supported silylone 24 and germylone $\mathbf{2 5}$ from $\mathbf{1}$ and $\mathbf{2}$, respectively, and the two-fold $\mathrm{ZnCl}_{2}$ adduct $\mathbf{2 6}$ from 1 .

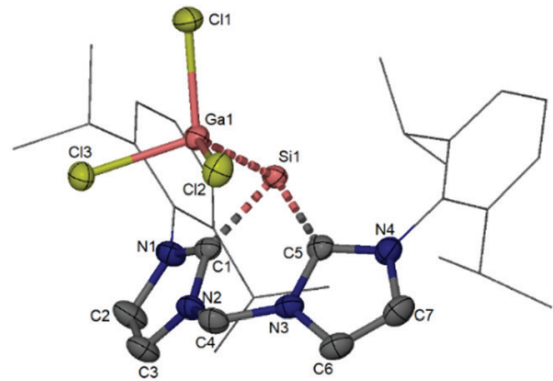

Fig. 4 Molecular structure of the silylone- $\mathrm{GaCl}_{3}$ adduct 24 (hydrogen atoms are omitted for clarity).

therein possess a trigonal planar geometry without any indication for a lone pair on the germanium centre.

The bis(NHC)-supported silylone 1 and germylone 2 react also readily with other group 13 Lewis acids such as $\mathrm{AlBr}_{3}$ and $\mathrm{BCl}_{3}$, but the desired products could not be isolated, presumably due to the formation of both mono and bis-Lewis-acid adducts. To our delight, a bis-Lewis-acid adduct 26 with silylone acting as a 2 -fold donor toward $\mathrm{ZnCl}_{2}$ has been obtained from silylone $\mathbf{1}$ and characterised structurally (Scheme 7). ${ }^{37}$ In the molecular structure of $\mathbf{2 6}$ the central silicon atom, coordinated by a chelating bis(NHC) and two $\mathrm{ZnCl}_{2}$ molecules, adopts a pseudotetrahedral coordination environment (Fig. 5). The coordination environment of the two $\mathrm{Zn}$ atoms in 26 is different: one in a trigonal planar geometry, the other additionally coordinated by a THF molecule.

Although the xanthene-based bis(NHSi)-supported silylone 3 and germylone $\mathbf{4}$ possess some double bond character between the silylene-Si atoms and the central silicon or germanium atom, they show coordination ability toward one and even two Lewis acids. This has been demonstrated by the Lewis adduct formation with $\mathrm{AlBr}_{3}$. The reaction of germylone 4 with one molar equiv. of $\mathrm{AlBr}_{3}$ leads smoothly to the mono- $\mathrm{AlBr}_{3}$ adduct 27 which can be isolated as an orange solid (Scheme 8). ${ }^{30}$ In the molecular structure of 27 , the germanium atom adopts a pseudotetrahedral coordination geometry, implying the presence of a lone pair of electrons at the apex.

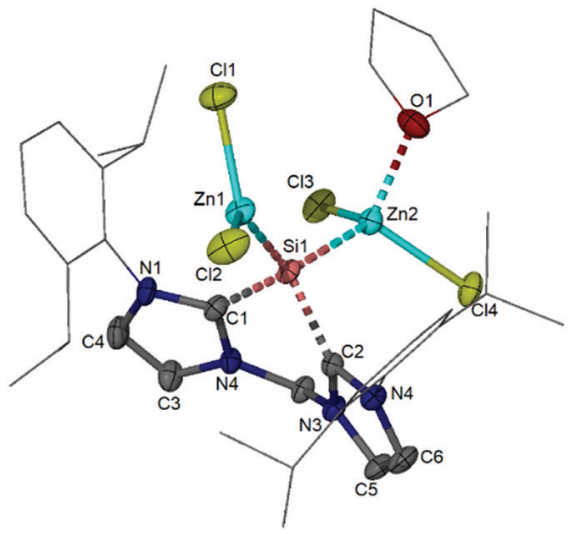

Fig. 5 Molecular structure of the silylone- $\mathrm{ZnCl}_{2}$ adduct $\mathbf{2 6}$ (hydrogen atoms are omitted for clarity). 


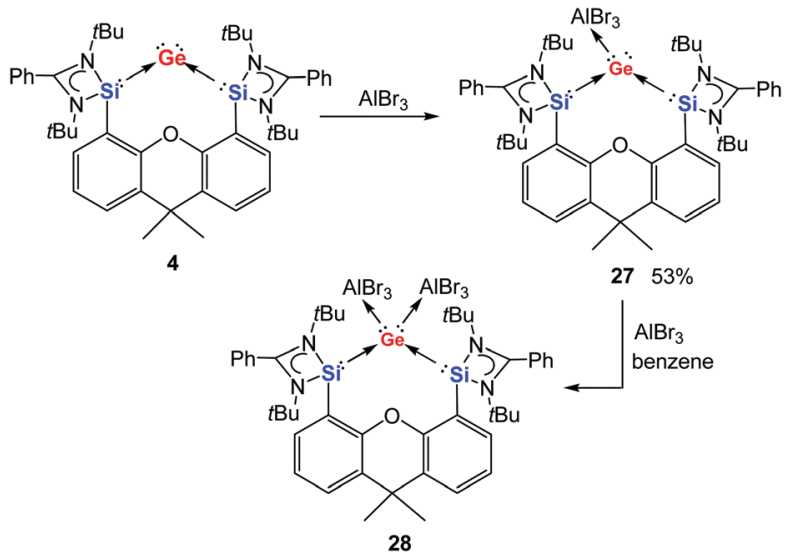

Scheme 8 Formation of $\mathrm{AlBr}_{3}$ adducts $\mathbf{2 7}$ and $\mathbf{2 8}$ with xanthene-based bis(NHSi) germylone 4 .

Further coordination of $\mathrm{AlBr}_{3}$ with the mono-AlBr 3 adduct 27 to form the bis- $\mathrm{AlBr}_{3}$ adduct 28 is dependent on the solvent used (Scheme 8 ). ${ }^{30}$ Due to the stronger coordination ability of the donor solvents than that of 27, the desired bis-AlBr 3 adduct 28 could not be formed in ethereal solvent such as $\mathrm{Et}_{2} \mathrm{O}$ and THF even in the presence of the 20-fold molar excess of $\mathrm{AlBr}_{3}$. In benzene solutions, however, the adduct $\mathbf{2 8}$ can be obtained in the form of a white precipitate and characterised with XRD.

Interestingly, the $o$-carborane-bis(NHSi)-supported germylone 6 can react with $\mathrm{GeCl}_{2}$-dioxane, yielding exclusively complex 29 as a yellow solid regardless of the ratio of starting materials (Scheme 9). ${ }^{31}$ The crystal structure of 29 reveals a four-coordinate germanium centre attached to two germyloneGe atoms and two chlorine atoms. The central germanium centre adopts a seesaw coordination geometry with both chloride atoms located at the axial positions, suggesting that one of the three equatorial positions is occupied by a lone pair (Fig. 6). Compound 29 can be viewed as a $\mathrm{Ge}^{0}{ }_{2} \mathrm{Ge}^{\mathrm{II}}$ adduct, in which each $\mathrm{Ge}^{0}$ atom still features a stereochemically active lone pair, as indicated by its pyramidal coordination geometry. Notably, this complex can serve as a precursor for the novel bis(NHSi)-supported

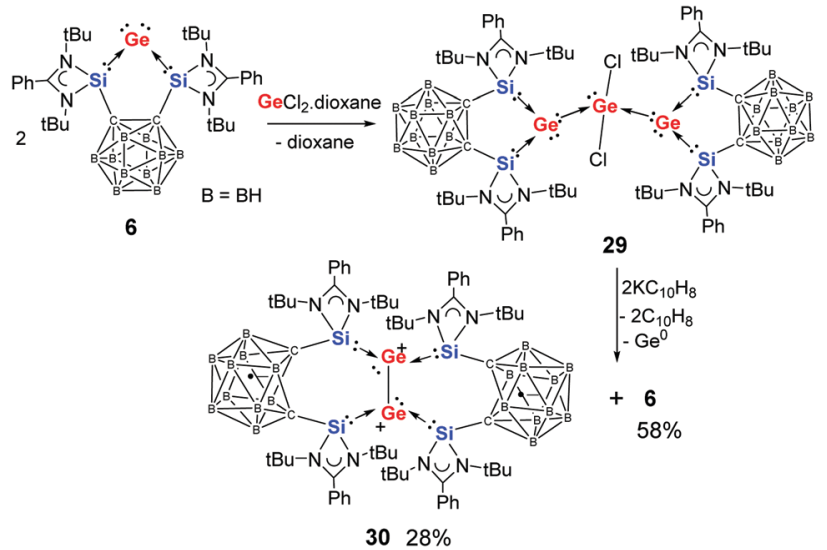

Scheme 9 Formation of the two-fold germylone- $\mathrm{GeCl}_{2}$ adduct $\mathbf{2 9}$ and its reduction affording germylone $\mathbf{6}$ and the diradical dimer $\mathbf{3 0}$.

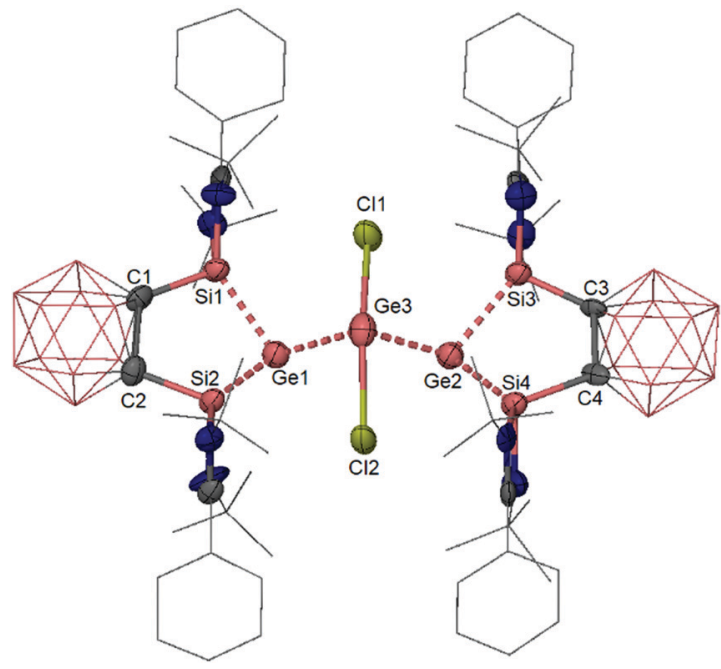

Fig. 6 Molecular structure of the $\mathrm{GeCl}_{2}$-germylone adduct 29 (hydrogen atoms are omitted for clarity).

neutral $\mathrm{Ge}_{2}$ complex 30 (Scheme 9), which is obtained as a minor isolable product along with germylone 6 when reduced using two molar equiv. of potassium naphthalenide.

It is of note, due to the electron-rich nature of silylones and germylones, some of them can also act as reducing agents towards germanium(II) and silicon(II) dichloride complexes to generate elemental germanium and silicon, respectively, as shown in Scheme 10. For instance, the reaction of silylone 1 or germylone 2 with $\mathrm{SiCl}_{2}\left({ }^{\mathrm{D}} \mathrm{NHC}\right)$ leads to the known disilicon(0) complex $\left({ }^{\mathrm{D}} \mathrm{NHC}\right) \mathrm{Si}=\mathrm{Si}\left({ }^{\mathrm{D}} \mathrm{NHC}\right),{ }^{53}$ along with elemental silicon. In both cases, $\mathbf{1}$ and $\mathbf{2}$ convert back to their respective precursors $\mathbf{1 1}$ and $\mathbf{1 2}$ during the process. Similarly, utilising the germylone $\mathbf{K}$ (Chart 2), Nikonov and co-workers explored very recently the reaction with $\mathrm{GeCl}_{2}$ (dioxane), giving rise to the corresponding $[\mathrm{GeCl}]^{+}$complex with $\left[\mathrm{GeCl}_{3}\right]^{-}$as counterion. ${ }^{23}$

\subsection{Oxidation with elemental chalcogens}

Since silylones bear a silicon(0) centre, they may be transformed with elemental chalcogens to monomeric silicon(II) and silicon(Iv)
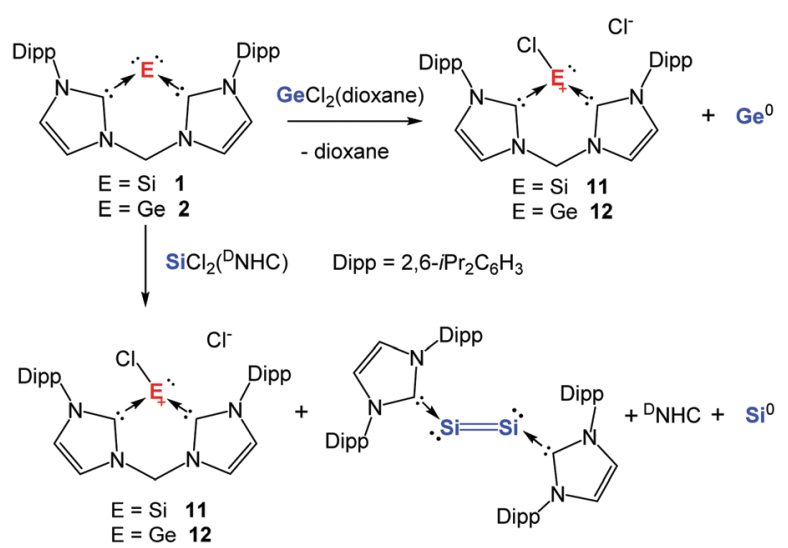

Scheme 10 Reaction of silylone 1 and germylone 2 with $\mathrm{GeCl}_{2}$ (dioxane) and $\mathrm{SiCl}_{2}\left({ }^{\mathrm{D}} \mathrm{NHC}\right)$ complexes, respectively. 
chalcogenide complexes. In fact, facile reaction between silylone 1 with elemental sulphur leads to the bis(NHC)-supported $\mathrm{SiS}_{2}$ complex 31 as a colourless powder (Scheme 11). ${ }^{73}$ Moreover, compound 31 can coordinate with $\mathrm{GaCl}_{3}$ to form a push-pull complex 32 as colourless crystals suitable for XRD characterisation. Alternatively, adduct 32 can be prepared through the reaction of the $\mathrm{GaCl}_{3}$ complex 24 with elemental sulphur. The molecular structure of 32 reveals a strongly bent $\mathrm{S}=\mathrm{Si}=\mathrm{S}$ unit with $\mathrm{GaCl}_{3}$ coordinating to one of the sulphide atoms and the new silicon(Iv) centre remains ligated to the bis(NHC).

In contrast to the reaction of $\mathbf{2 4}$ with sulphur, which leads directly to a silicon(Iv) species, the reaction of $\mathbf{2 4}$ with red selenium $\left(\mathrm{Se}_{8}\right)$ is controllable and solvent dependent, affording the two silicon selenide complexes 33 and 34 (Scheme 11). ${ }^{76}$ In acetonitrile, $\mathbf{2 4}$ reacts with red selenium at room temperature for $3 \mathrm{~h}$ to afford the silicon(II) selenide $\mathbf{3 3}$ as an isolable product, while the reaction of $\mathbf{2 4}$ with red selenium in THF furnishes directly the silicon(Iv) selenide 34. Conversion of the silicon monoselenide 33 to the diselenide $\mathbf{3 4}$ with red selenium is observed in THF. As expected, compound $\mathbf{3 4}$ is isostructural with its sulphur analogue 32, baring a strongly bent $\mathrm{SiSe}_{2}$ moiety. The molecular structure of $\mathbf{3 3}$ features an $: \mathrm{Si}=\mathrm{Se}$ moiety with a terminal $=$ Se and a tetrahedrally coordinated

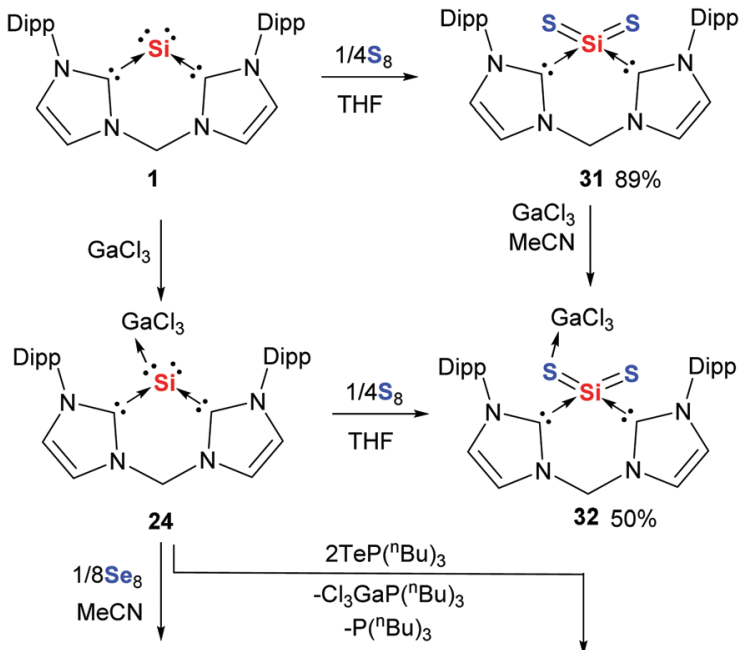

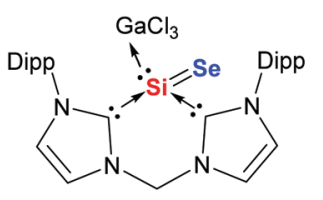

$3365 \%$

$$
\begin{gathered}
1 / 8 \mathrm{Se}_{8} \\
\mathrm{THF}
\end{gathered}
$$

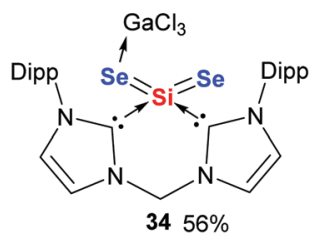

Scheme 11 Reaction of silylone 1 and its $\mathrm{GaCl}_{3}$ complex 24 with elemental sulphur, selenium, and $\operatorname{TeP}\left({ }^{n} \mathrm{Bu}\right)_{3}$, respectively. silicon centre, ligated by the bis(NHC) and the gallium atom of $\mathrm{GaCl}_{3}$. The silicon-selenium distance (ca. $2.14 \AA$ ) of 33 suggests appreciable $\mathrm{Si}-\mathrm{Se}$ double bond character. It should be mentioned that complexes of heavier analogues of $\mathrm{CO}$ are rare. Known examples include $\mathrm{SnO},{ }^{77} \mathrm{PbO},{ }^{77}$ and $\mathrm{PbSe}^{78}$ coordinated by supporting ligands at both ends of the heavy $\mathrm{CO}$ analogues. Complex 33 represents the first example of a heavy homologue of CO complexes only supported at the group 14 (silicon) site.

In sharp contrast to the reaction of $\mathbf{2 4}$ with elemental sulphur and selenium, 24 does not react with elemental tellurium. Utilising $\mathrm{Te}=\mathrm{P}\left({ }^{n} \mathrm{Bu}\right)_{3}$ as a more reactive tellurium source, however, 24 can be transformed to the isolable bis(NHC)SiTe 235 as orange crystals (Scheme 11). ${ }^{76}$ The molecular structure of $\mathbf{3 5}$ established by XRD exhibits a strongly bent $\mathrm{Te}=\mathrm{Si}=$ Te moiety (Te-Si-Te angle: $128.4^{\circ}$ ) with the silicon centre additionally coordinated by the bis(NHC) ligand (Fig. 7). The two Si-Te distances are slightly different [2.389(4) and 2.436(2) $\AA$ ]. Compounds 32, 34, and 35 represent the first series of monomeric $\mathrm{SiX}_{2}\left(\mathrm{X}=\mathrm{S}\right.$, Se, Te) complexes as heavy homologues of $\mathrm{CO}_{2}$. Very recently, starting from the silicon(0) complex $\mathbf{K}$, Lips obtained another series of $\mathrm{SiX}_{2}$ complexes $\mathbf{K}-\mathbf{1}$ (Chart 3) with one of the chalcogen atoms interacting with the silicon atom of the SiN(Dipp) moiety of the ligand as well. ${ }^{79}$ It is noted that dimeric $\operatorname{SiX}_{2}\left(X=S,{ }^{80}\right.$ $\mathrm{Se},{ }^{81} \mathrm{Te}^{82}$ ) stabilised by NHC or cAAC have also been structurally characterised. A donor and acceptor supported $\mathrm{SiO}_{2}$ complex has also been described recently. ${ }^{83}$

Akin to 24, the germanium analogue 25 reacts readily with elemental sulphur to afford the $\mathrm{GeS}_{2}$ complex 36 as a colourless solid (Scheme 12). ${ }^{74}$ While attempts to get the germanium(II) monosulphide complex from 25 failed, the complexes of germanium(II) monoselenide 37 and monotelluride 38 result from the reaction of $\mathbf{2 5}$ with red selenium and elemental tellurium, respectively. Moreover, the germanium(II) complex 37 can be converted to the germanium(Iv) species 39 with red selenium in THF. Remarkably, treatment of 37 and 39 with elemental sulphur leads to the $\mathrm{GeS}_{2}$ complex 36 under elimination of elemental selenium and tellurium, respectively.

The molecular structures of the germanium(rv) dichalcogenides 36 and 39 resemble those of the silicon analogues 32 and 34. In contrast, the molecular structures of germanium(II) complexes 37 and 38 show completely different structures compared with that of the silicon monoselenide complex 33 . Complexes $\mathbf{3 7}$ and $\mathbf{3 8}$ possess a lone pair at the germanium

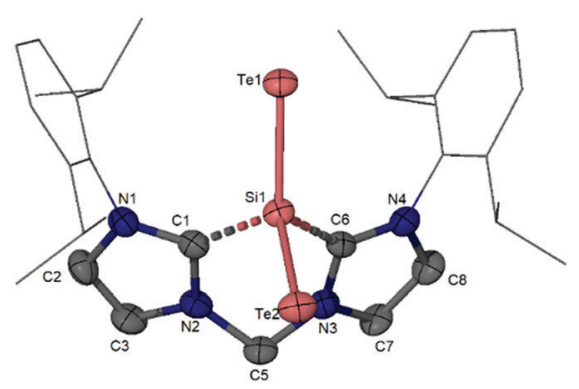

Fig. 7 Molecular structure of the bis(NHC)-supported $\mathrm{SiTe}_{2}$ complex 35 (hydrogen atoms are omitted for clarity). 

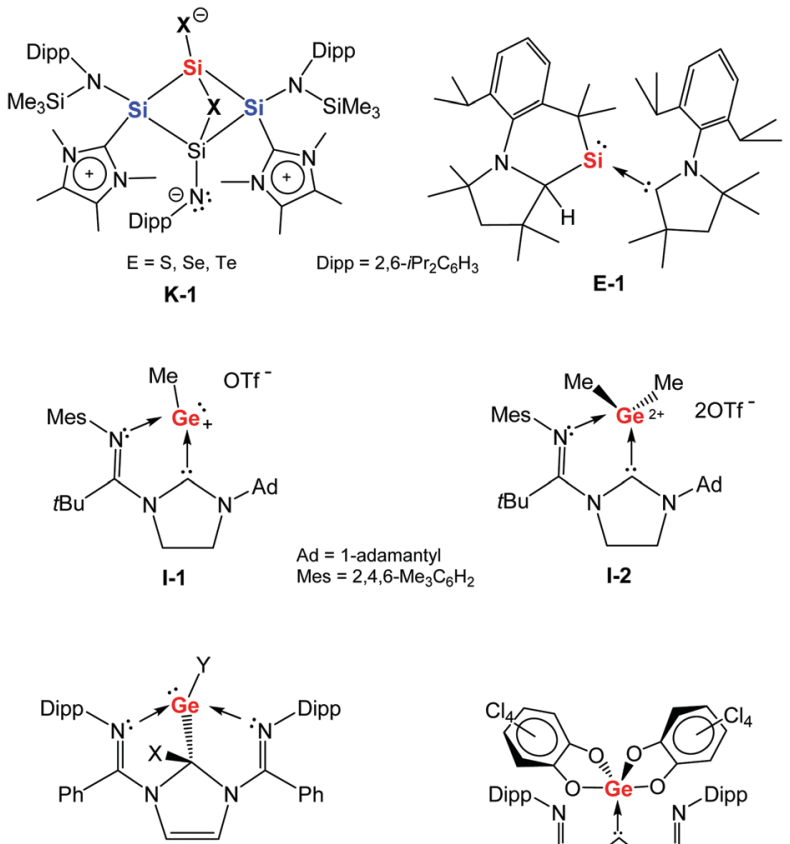

$\mathrm{H}-1 \mathrm{X}=\mathrm{H}, \mathrm{Y}=\mathrm{Cl}$

$\mathrm{H}-2 \mathrm{X}=\mathrm{Me}, \mathrm{Y}=\mathrm{I}$

$\mathrm{H}-3 \mathrm{X}=\mathrm{Ph}, \mathrm{Y}=\mathrm{I}$

$\mathrm{H}-4 \mathrm{X}=\mathrm{C}_{5} \mathrm{~F}_{4} \mathrm{~N}, \mathrm{Y}=\mathrm{F}$

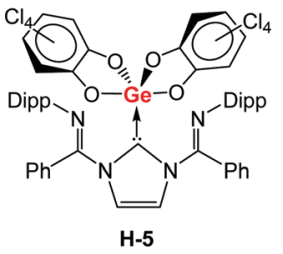

Chart 3 Oxidation products $\mathrm{K}-\mathbf{1}, \mathrm{E}-\mathbf{1}, \mathbf{I}-\mathbf{1}, \mathbf{2}, \mathrm{H}-\mathbf{1}, \mathbf{2}, \mathbf{3}, \mathbf{4}, \mathbf{5}$ resulting from silylones $\mathbf{K}$ and $\mathbf{E}$ as well as germylones $\mathbf{I}$ and $\mathbf{H}$, respectively.

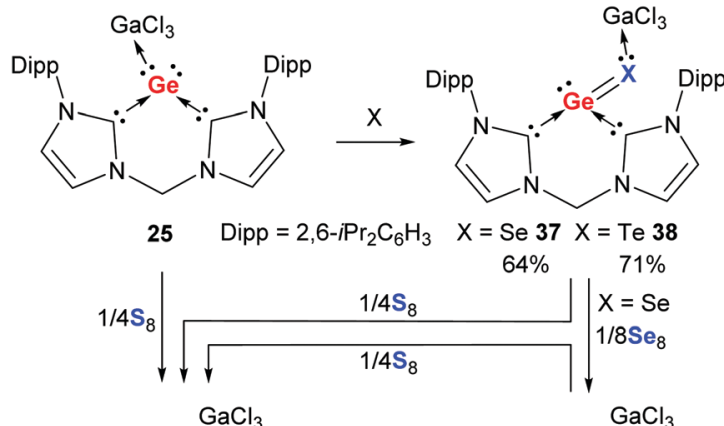

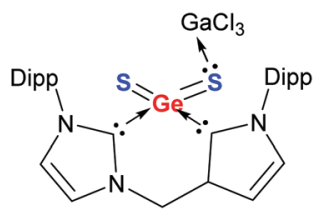

$3690 \%$

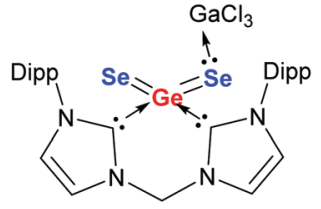

39
Scheme 12 Reaction of germylone- $\mathrm{GaCl}_{3}$ adduct 25 with elemental Sulphur, selenium, and tellurium to afford 36-39, respectively.

centre with the $\mathrm{GaCl}_{3}$ moiety coordinated to the Se and Te atoms, while 33 features a $\mathrm{Si}=$ Se bond and has the $\mathrm{GaCl}_{3}$ attached to the silicon centre. This marks a significant difference between divalent silicon and germanium centres in terms of coordination to a Lewis acid: the lone pair of silicon(II) is much more active than that of germanium(II).

\subsection{Activation of $\mathrm{CO}_{2}$ and $\mathrm{N}_{2} \mathrm{O}$}

Although silicon(0) and germanium(0) complexes are extremely sensitive toward dioxygen, leading to $\mathrm{SiO}_{2}$ or $\mathrm{GeO}_{2}$ with the

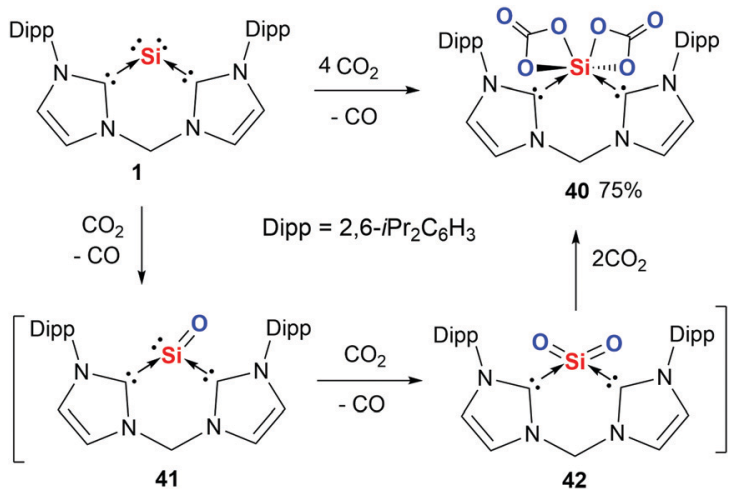

Scheme 13 Reaction of silylone 1 with $\mathrm{CO}_{2}$ to furnish $\mathbf{4 0}$ via the $\mathrm{SiO}$ and $\mathrm{SiO}_{2}$ intermediates $\mathbf{4 1}$ and $\mathbf{4 2}$.

liberation of their respective ligands, ${ }^{44}$ the bis(NHC)- and bis(NHSi)-supported silylones allowed us to control the extent of reaction, from which we were able to isolate several novel silicon compounds by using $\mathrm{CO}_{2}$ and $\mathrm{N}_{2} \mathrm{O}$ as oxygenation agents. For instance, the reaction of silylone 1 with $\mathrm{CO}_{2}$ at low temperature affords the silicon(Iv) dicarbonate complex (bis-NHC)Si( $\left(\mathrm{CO}_{3}\right)_{2} \mathbf{4 0}$ (Scheme 13). ${ }^{84}$ Indeed, the latter product represents the first isolable molecular silicon dicarbonate complex. According to DFT calculations, (bis-NHC)SiO 41 and (bis-NHC) $\mathrm{SiO}_{2} \mathbf{4 2}$ are formed as reactive intermediates during the reaction. The formation of $\mathbf{4 2}$ proceeds exergonically by only $-88 \mathrm{~kJ} \mathrm{~mol}^{-1}$ and 41 is even formed endergonically $\left(12 \mathrm{~kJ} \mathrm{~mol}^{-1}\right)$. Due to the extremely polar $\mathrm{Si}-\mathrm{O}$ bonds in $\mathbf{4 2}$, the reaction with two additional molecules of $\mathrm{CO}_{2}$ to afford 40 occurs with a free-energy gain of $-81 \mathrm{~kJ} \mathrm{~mol}^{-1}$. The calculated reaction free energies for the reaction of $\mathbf{1}$ with dioxygen are -236 and $-583 \mathrm{~kJ} \mathrm{~mol}^{-1}$ for the mono- and di-oxygenation respectively, rationalising the uncontrollable reaction with $\mathrm{O}_{2}$ mentioned above. It should be mentioned that the reaction of germylone 2 with $\mathrm{CO}_{2}$ led merely to the Lewis adduct (bis-NHC) $\left(\mathrm{CO}_{2}\right)_{2}$ along with a precipitate of $\mathrm{GeO}_{2}$.

While the reaction of bis(NHC)-supported silylone 1 with $\mathrm{N}_{2} \mathrm{O}$ remains uncontrollable, slow exposure of a diethyl ether solution of the bis(NHSi)-stablised silylone 3 to two molar equiv. of $\mathrm{N}_{2} \mathrm{O}$ leads to the gradual crystallisation of the novel silicon oxide complex 43 as yellow crystals (Scheme 14). ${ }^{28}$ In the presence of excess $\mathrm{N}_{2} \mathrm{O}$, silylone 3 is also partially oxidised to 43 by only two equiv. of $\mathrm{N}_{2} \mathrm{O}$. Presumably, further oxidation by $\mathrm{N}_{2} \mathrm{O}$ is prevented by the poor solubility of the product 43. In contrast, when a diethyl ether solution of $\mathbf{3}$ is mixed with $\mathrm{N}_{2} \mathrm{O}$ gas in a molar ratio of $1: 1$, compound 44 precipitates gradually as colourless crystals. Interestingly, the $\mathrm{Ph}$ group of the amidinato group is reduced/undergoes a cycloadditon. Notably, exposing $\mathbf{4 4}$ to excess $\mathrm{N}_{2} \mathrm{O}$ only causes its decomposition and no further oxidation to $\mathbf{4 3}$ is observed, excluding compound $\mathbf{4 4}$ as an intermediate in the formation of $\mathbf{4 3}$.

\subsection{Activation of $\sigma$ bonds in organic substrates}

With two high energy lone pairs, silylones and germylones are expected to readily activate a range of chemical bonds from 


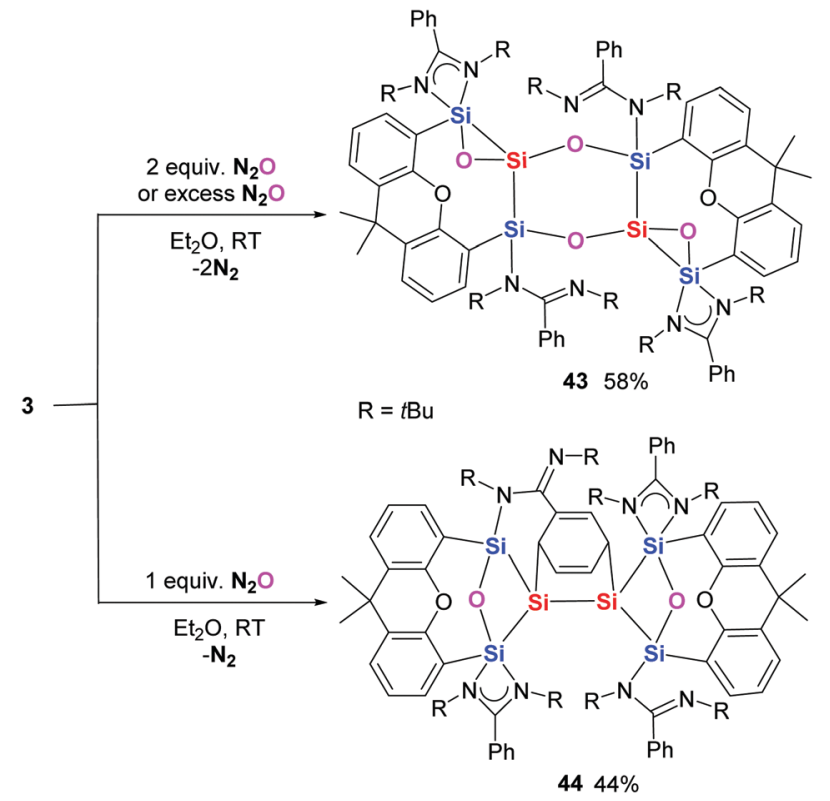

Scheme 14 Reaction of silylone 3 with $\mathrm{N}_{2} \mathrm{O}$ under different conditions to yield $\mathbf{4 3}$ and $\mathbf{4 4 .}$

suitable organic substrates, including $\mathrm{E}-\mathrm{H}(\mathrm{E}=\mathrm{B}, \mathrm{C}, \mathrm{N})$ and $\mathrm{C}-\mathrm{X}$ $(\mathrm{X}=$ halogen) bonds. In these addition reactions, the group 14(0) centre can be oxidised to the +2 or +4 oxidation state, whilst the ligand acts in a cooperative manner. With the reported ylidones featuring a variety of supporting ligands, the acceptor orbitals are specific to each complex and substrate, affecting the outcome of reaction significantly. Although $(\mathrm{cAAC})_{2} \mathrm{Si} \mathbf{E}$ is relatively stable, Roesky and co-workers described an intramolecular insertion of the silicon(0) centre into one of the Dipp $\mathrm{C}-\mathrm{H}$ bonds of the supporting cAAC ligands, yielding the cyclic cAAC-stabilised silylene E-1 (Chart 3). ${ }^{85}$ This transformation was induced by treating the silylone $\mathbf{E}$ with elemental potassium and believed to proceed via a cAAC-carbon-centred radical anion, rather than the result of an intrinsic reactivity of the $\mathrm{Si}^{0}$ site in the silylone. In a nucleophilic substitution type reaction, germylone $\mathbf{I}$ can be controllably methylated with one molar equiv. of methyl trifluoromethanesulfonate (MeOTf) to furnish the germyliumylidene ion I-1 (Chart 3) and with two equiv. of MeOTf to afford the Ge(Iv) species I-2, shown by Kinjo and co-workers. ${ }^{75}$ In the case of the (dimNHC)Ge $\mathbf{H}$ developed in 2020 by Nikonov, ${ }^{23}$ the carbene donor of the tridentate ligand is involved in $\mathrm{H} / \mathrm{C}-\mathrm{X}(\mathrm{X}=$ halogen $)$ activation. In reactions with $\mathrm{HCl}, \mathrm{MeI}, \mathrm{PhI}$ and $\mathrm{C}_{5} \mathrm{~F}_{5} \mathrm{~N}$, a Ge-X bond and a $\mathrm{C}-\mathrm{H}$ or $\mathrm{C}-\mathrm{C}$ bond form at the carbene- $\mathrm{C}$ to give the new species H-1-4 (Chart 3) respectively. ${ }^{23}$ Additionally, the germylone $\mathbf{H}$ also undergoes a cycloaddition reaction with the $\mathrm{C}=\mathrm{O}$ moieties in tetrachloro-o-benzoquinone to afford an NHCsupported Ge(rv) bis(catecholate) H-5 (Chart 3).

Using the bis(NHSi)-supported germylone 4, B-H activation can be achieved. Treating compound 4 with 1 molar equiv. of 9borabicyclo[3.3.1] nonane (9-BBN) in toluene at room temperature yields the unexpected silylene-stabilised boryl(silyl)germylene $\mathbf{4 5}$ as dark red crystals (Scheme 15). ${ }^{30}$ It became evident from the structure of $\mathbf{4 5}$ that the boron-bound hydrogen atom of 9-BBN is
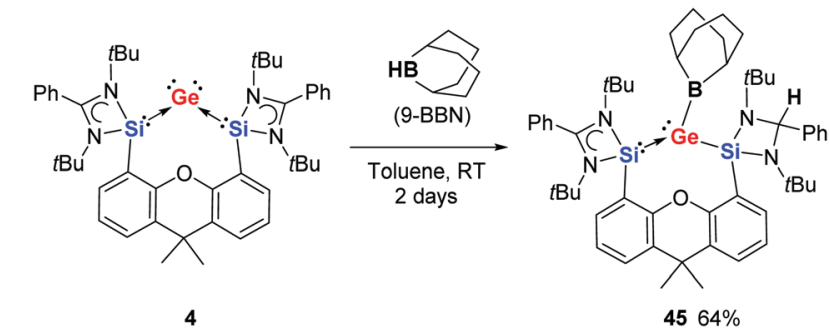

Scheme 15 Reaction of germylone 4 with 9-BBN to give 45
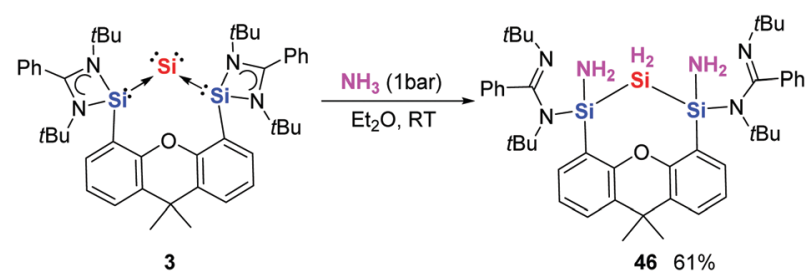

Scheme 16 Activation of $\mathrm{NH}_{3}$ with silylone 3 to generate 46

added onto the carbon atom of the amidinate ring. At the $\mathrm{Ge}^{0}$ site we see oxidation of $\mathrm{Ge}^{0}$ to $\mathrm{Ge}^{\mathrm{II}}$ with a new $\mathrm{Ge}-\mathrm{B}$ and $\mathrm{Ge}-\mathrm{Si}$ bond. The NHSi ligand acts as the hydride acceptor in this case leading to the formation of an electron-sharing $\mathrm{Ge}-\mathrm{Si}$ bond and saturation of the amidinato ring.

Inspired by the recent reports using low-valent group 14 species for activating $\mathrm{NH}_{3},{ }^{86-88}$ we investigated the reactivity of silylone 3 toward $\mathrm{NH}_{3}$. Exposure of 3 to 1 bar of ammonia at room temperature leads to the isolation of 1,3-diaminotrisilane 46 as colourless crystals (Scheme 16). ${ }^{28}$ Here we see two $\mathrm{N}-\mathrm{H}$ bonds from two ammonia molecules add across the $\mathrm{Si}^{0}-\mathrm{Si}^{\mathrm{II}}$ bond to form two new $\mathrm{Si}-\mathrm{H}$ bonds and two new $\mathrm{Si}-\mathrm{N}$ bonds. All the silicon centres are fully oxidised to the +4 oxidation state. Notably, activation of $\mathrm{NH}_{3}$ by germylone 4 is also possible according to in situ NMR, affording a germanium analogue of 46 that is unstable and gradually converted to an unidentified mixture.

\subsection{Forming FLPs for small molecule activation}

Low valent silicon compounds such as acyclic silylenes and silicon-silicon multiple bond-containing species have recently demonstrated their ability for activating $\mathrm{H}_{2}$ and ethylene. ${ }^{89-95}$ This progress prompted us to examine the reactivity of silylones toward these gases. Unfortunately, monitoring of the ${ }^{1} \mathrm{H}$ NMR spectra of silylone 3 in $\mathrm{H}_{2}$ or $\mathrm{C}_{2} \mathrm{H}_{4}$ atmosphere reveals that the silylone is inert toward either of these gases, due to the lack of an appropriate acceptor orbital at the $\mathrm{Si}^{0}$ centre or on the ligand. Frustrated Lewis Pairs (FLPs) take advantage of the potential for cooperation between unquenched bulky Lewis bases and Lewis acids to activate poorly reactive small molecules and have recently attracted much attention. ${ }^{96,97}$ Considering the electron-rich character of the bulky silylone 3 and germylone 4, we expected that it either could behave as a suitable Lewis base partner in conjunction with a bulky Lewis acid for the activation of $\mathrm{H}_{2}$. Accordingly, a mixture of 3 and 


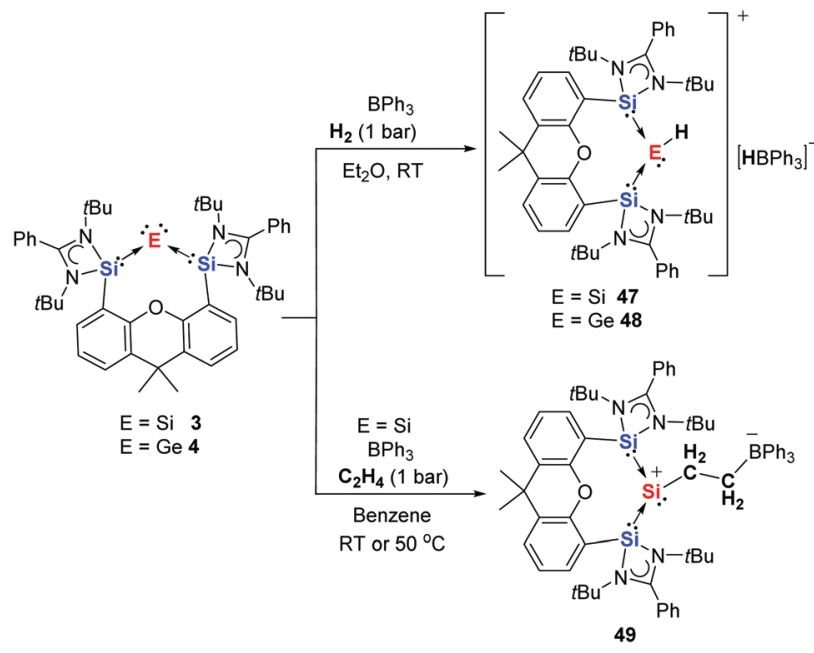

Scheme 17 Activation of $\mathrm{H}_{2}$ and $\mathrm{C}_{2} \mathrm{H}_{4}$ with silylone 3 and germylone 4, respectively, in the presence of $\mathrm{BPh}_{3}$ to generate 47-49.

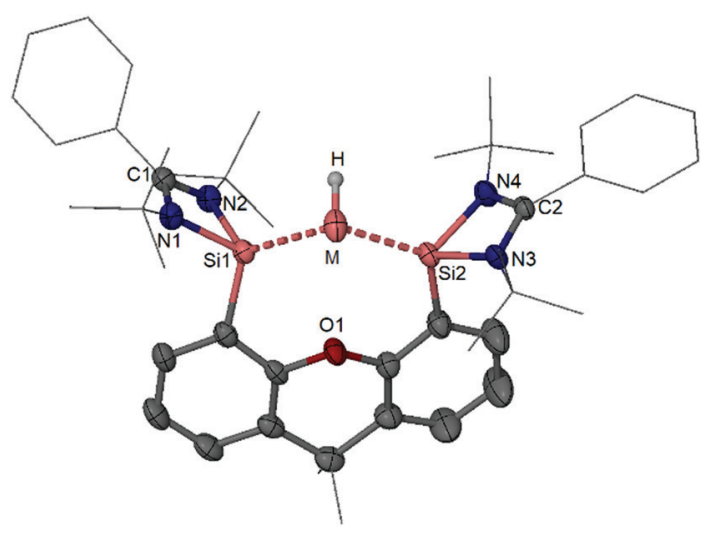

Fig. 8 Molecular structures of the cations of $\mathbf{4 7}(\mathrm{M}=\mathrm{Si})$ and $\mathbf{4 8}(\mathrm{M}=\mathrm{Ge})$ [hydrogen atoms (except for that at $\mathrm{M}$ atom) are omitted for clarity].

$\mathrm{BPh}_{3}$ was exposed to 1 bar of hydrogen gas, which results in heterolytic $\mathrm{H}_{2}$ cleavage and the formation of compound $\mathbf{4 7}$ as a yellow salt (Scheme 17). ${ }^{28}$ Formation of the $\mathrm{Si}-\mathrm{H}$ and $\mathrm{B}-\mathrm{H}$ moieties have been unambiguously confirmed by NMR spectroscopy and XRD (Fig. 8). The cation of 47 represents the first $[: \mathrm{SiH}]^{+}$complex stabilised by a bis-silylene.

Similarly, the bis(NHSi)-supported germylone 4 can also serve as a bulky base with $\mathrm{BPh}_{3}$ to perform FLP activity for hydrogen activation, affording compound 48 as an isolable product (Scheme 17 and Fig. 8). ${ }^{30}$ We have also shown that silylone 3 and $\mathrm{BPh}_{3}$ can activate ethene via a similar FLP mechanism leading to the novel zwitterionic complex $49 .^{28}$ For the first time, we have shown that ylidones can also be applied as bulky bases in FLP chemistry, following the previous success of silylenes and germylenes in this area already. ${ }^{98-101}$

\subsection{Si-Si and Ge-Ge coupling reactions}

Generally, disilicon and digermanium complexes result from the reduction of monatomic silicon or germanium halides with alkaline metals through $\mathrm{Si}-\mathrm{Si}$ and Ge-Ge coupling,

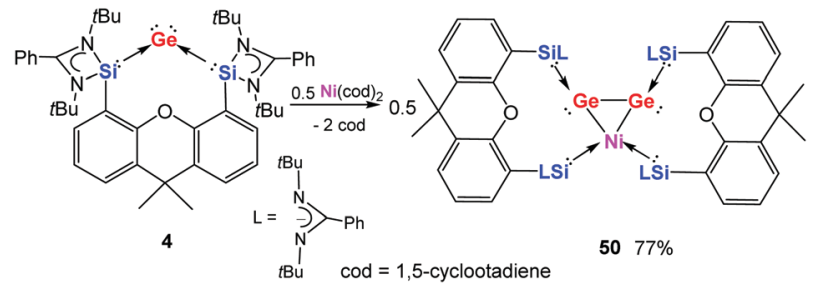

Scheme 18 Formation of the $\mathrm{NiGe}_{2}$ complex $\mathbf{5 0}$ via reaction of $\mathbf{4}$ with $\mathrm{Ni}(\mathrm{cod})_{2}$.

respectively. ${ }^{53,54,102,103}$ However, the homocoupling of isolable monatomic $\mathrm{Si}^{0}$ and $\mathrm{Ge}^{0}$ was still unknown. Remarkably, treatment of germylone 4 with $\mathrm{Ni}(\operatorname{cod})_{2}(\operatorname{cod}=1,5$-cyclooctadiene $)$ in a molar ratio of $2: 1$ in diethyl ether allows the isolation of the novel $\mathrm{Ge}_{2} \mathrm{Ni}$ complex $\mathbf{5 0}$ as dark-brown crystals (Scheme 18). ${ }^{30}$ In the crystal structure, $\mathbf{5 0}$ features a three-membered $\mathrm{Ge}_{2} \mathrm{Ni}$ ring with the Ni centre adopting a square planar geometry (Fig. 9). The Ge-Ge distance [2.470(1) ̊] and the Ni-Ge distances $[2.425(2)$ and $2.443(2) \AA]$ suggest that $\mathbf{5 0}$ can be described as a bis(NHSi)-stabilised $\mathrm{Ge}_{2} \mathrm{Ni}$ complex bearing a Ge(I)-Ge(I)-Ni(II) metallacycle. This metallacycle must be favoured over a $\left[\eta^{2}\right.$-(digermene) $] \mathrm{Ni}(0) \pi$-complex. ${ }^{104}$ It is generated after $\mathrm{Ge} \rightarrow \mathrm{Ni}$ coordination through the reductive coupling of the two germylone- $\mathrm{Ge}^{0}$ centres and insertion of the $\mathrm{Ni}$ atom to two of the $\mathrm{Si} \rightarrow \mathrm{Ge}$ dative bonds.

Without the presence of transition metals, the Si-Si coupling of silylone $\mathbf{5}$ occurs when $\mathbf{5}$ is reduced with one molar equiv. of potassium naphthalenide, furnishing the intriguing bis(NHSi)-supported disilicon complex $\mathbf{5 1}$ as a red crystalline solid (Scheme 19). ${ }^{29}$ Overall, the one-electron reduction leads to the net movement of two electrons into the carborane cage with the loss of one electron at $\mathrm{Si}^{0}$ to give $\mathrm{Si}^{\mathrm{I}}$. According to DFT calculations, the latter reduction process can be encoded with four sub-steps: (i) one-electron reduction of one amidinato ligand of 5 to form 5a (Scheme 19); (ii) electron transfer to the ortho-carborane cluster in $\mathbf{5 a}$ to afford $\mathbf{5} \mathbf{b}$ with a radical carborane cluster; (iii) intramolecular one-electron oxidation of the $\mathrm{Si}^{0}$ atom in $\mathbf{5 b}$ and rearrangement of the carborane cluster core to form the intermediate $\mathbf{5 c}$ with a radical silicon centre

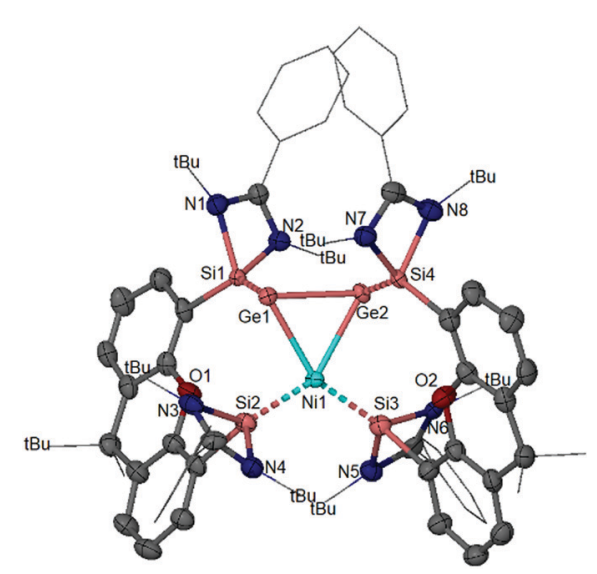

Fig. 9 Molecular structure of $\mathbf{5 0}$ (hydrogen atoms are omitted for clarity). 

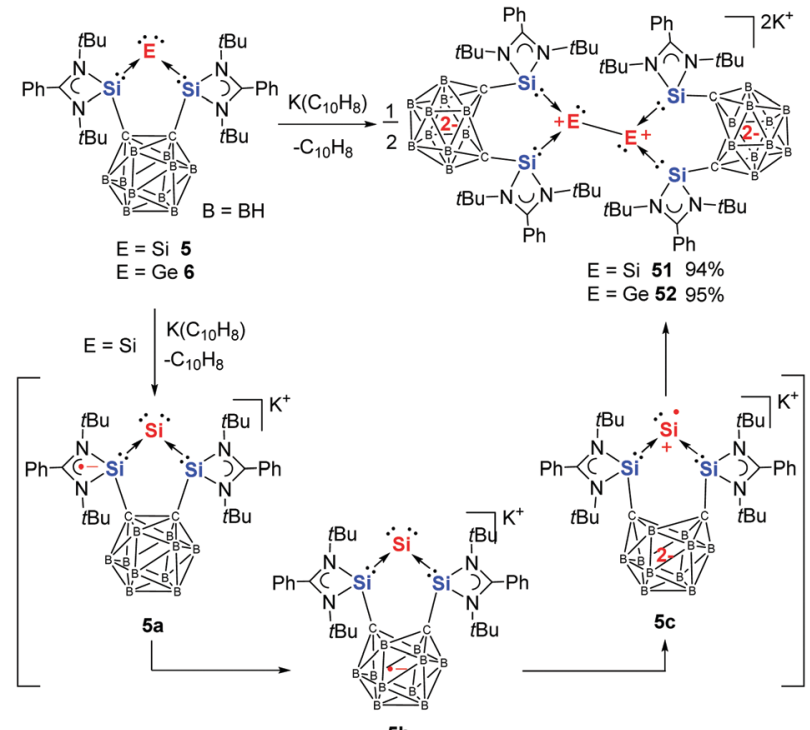

Scheme 19 One-electron reduction of silylone 5 and germylone 6 to generate the bis(NHSi)-supported disillicon(1) complex 51 and digermanium(I) $\mathbf{5 2}$ via the proposed radical species $\mathbf{5 a - c}$.

and a dianionic nido-carborane core; and (iv) Si-Si homocoupling of $\mathbf{5 c}$ to yield the final product $\mathbf{5 1}$.

In the crystal structure of $\mathbf{5 1}$, the two coupled silicon atoms are linked by a normal $\mathrm{Si}-\mathrm{Si}$ single bond and each adopts a trigonal-pyramidal geometry with a lone pair of electrons. ${ }^{29}$ Therefore, the coupling product $\mathbf{5 1}$ represents a bis(NHSi) supported $\left[\mathrm{Si}^{\mathrm{I}}-\mathrm{Si}^{\mathrm{I}}\right]^{2+}$ dication, significantly different from the NHC-stabilised neutral $\left[\mathrm{Si}^{0}=\mathrm{Si}^{0}\right]$ complex described by Robinson. ${ }^{53}$ Starting from germylone $\mathbf{6}$, the digermanium analogue 52 can also be achieved by following the same synthetic protocol mentioned above for $\mathbf{5 1}$ (Scheme 19). ${ }^{31}$

Although the latter homocoupling of the silylone and germylone results from reduction with potassium naphthalenide, the silicon and germanium centres are actually oxidised from zero to +1 . This prompted us to conduct the one-electron oxidation of germylone 6 with $\left[\mathrm{Cp}_{2} \mathrm{Fe}\right]\left[\mathrm{B}\left(\mathrm{C}_{6} \mathrm{H}_{3}\left\{\mathrm{CF}_{3}\right\}_{2}\right)_{4}\right]$ in a molar ratio of $1: 1$ (Scheme 20). ${ }^{31}$ To our delight, the oxidation led to the isolable $\left[\mathrm{Ge}^{\mathrm{I}}-\mathrm{Ge}^{\mathrm{I}}\right]$ coupling compound 53 as an orange solid, with no reduction of the carborane. Compound 53 crystallised as a separate ion pair with a $\mathrm{Ge}_{2}$-containing dication and two borate counteranions. Similarly to the dianion of $\mathbf{5 2}$, the dication of $\mathbf{5 3}$ features two germanium atoms in a

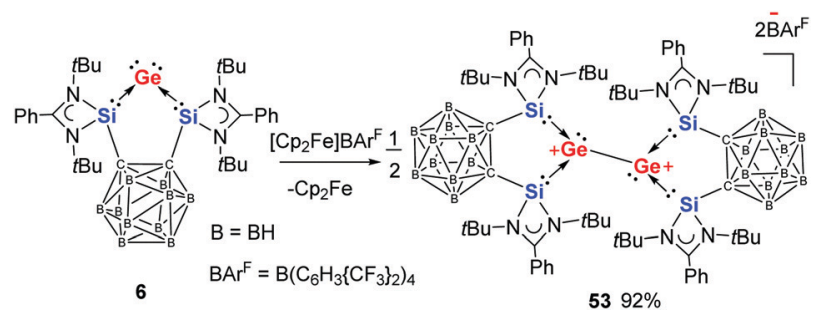

Scheme 20 One-electron oxidation of germylone 6 to give the bis(NHSi)-supported digermanium(ı) complex 53

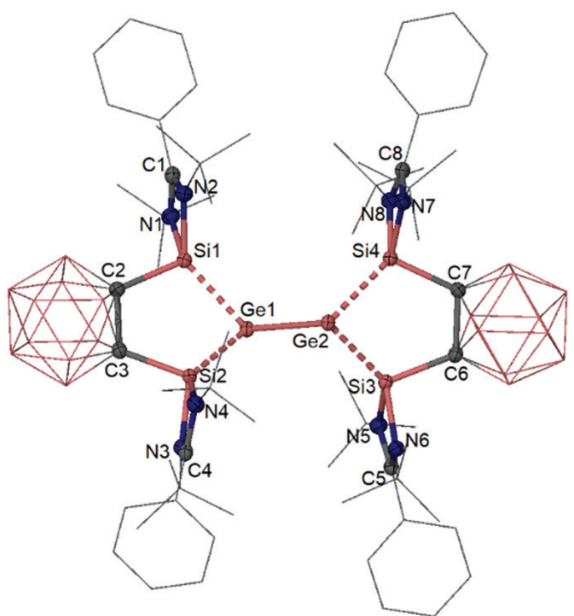

Fig. 10 Molecular structure of the cation in $\mathbf{5 3}$ (hydrogen atoms are omitted for clarity).

trigonal-pyramidal coordination environment (Fig. 10). The dication in $\mathbf{5 3}$ and the dianion in $\mathbf{5 2}$ both can be considered as a $\left[\mathrm{Ge}^{\mathrm{I}}-\mathrm{Ge}^{\mathrm{I}}\right]^{2+}$ complex supported by the bis(NHSi) ligand. In sharp contrast to the dianionic nido-carborane core of 52, compound $\mathbf{5 3}$ possesses a neutral closo-carborane core.

\section{Conclusions and outlook}

Judicious use of strongly donating ligands has enabled access to a new chemical space with isolable complexes of single, zerovalent silicon and germanium atoms. Several intriguing stable silylones and germylones have thus far been synthesised and structurally characterised by a few research groups in recent years. In this feature article, we have highlighted the chelating bis(NHC)- and bis(NHSi)-supported silylones and germylones. Due to their striking electronic and steric situations, the bis(NHC)- and bis(NHSi)-stabilised $\mathrm{Si}^{0}$ and $\mathrm{Ge}^{0}$ compounds allowed us to explore the intrinsic reactivities of such fascinating zero-valent species.

As expected for a genuine silylone and a germylone, the silicon(0) and germanium(0) species can form 1:1 and even 1:2 Lewis adducts with the two lone pairs of electrons at the $\mathrm{Si}^{0}$ or $\mathrm{Ge}^{0}$ centres. With the central silicon and germanium atoms in the zero oxidation state, they can serve as intriguing building blocks with elemental chalcogens for synthesis of isolable heavy $\mathrm{CO}$ and $\mathrm{CO}_{2}$ homologues including complexes of SiSe, $\mathrm{SiS}_{2}$, and $\mathrm{SiTe}_{2}$. Moreover, these silylones and germylones can readily mediate the activation of small molecules such as $\mathrm{CO}_{2}$, $\mathrm{N}_{2} \mathrm{O}$, and $\mathrm{NH}_{3}$ in a controlled manner and other bonds such as $\mathrm{E}-\mathrm{H}(\mathrm{E}=\mathrm{B}, \mathrm{C})$ and $\mathrm{H} / \mathrm{C}-\mathrm{X}(\mathrm{X}=$ halogen $)$, etc. They can also act as bulky Lewis bases to form FLPs with $\mathrm{BPh}_{3}$ for $\mathrm{H}_{2}$ and $\mathrm{C}_{2} \mathrm{H}_{4}$ activation. Finally, homocoupling of the central atoms of silylones and germylones has also been observed under reducing or oxidising conditions. The impressive reactivity of these bis(NHC)- and bis(NHSi)-supported silylones and germylones results from both the strongly donating nature and chelating structural effect of the bis(NHC) and bis(NHSi) ligands, which 
make the central silicon or germanium atoms highly electron rich as well as providing necessary kinetic protection during each transformation.

Despite the current progress described in this feature article, the chemistry of monatomic zero-valent silicon and germanium complexes remains in its infancy. Discovery of their remarkable electronic structure, with two extremely active lone pairs at a single Si or Ge site, has begun to be translated to wide-ranging and unprecedented reactivity. With the increasing availability of new strongly donating ligands, more examples with differing reactivity are likely to be developed shortly. The coordination chemistry of silylones and germylones, in particular, is promising due to the electron-richness of the group 14(0) atom and its capacity to coordinate to 1 or 2 metal sites simultaneously. It seems possible that ylidones could act as verstatile ligands in the manner of cAACs or NHCs for stabilizing novel low valent main group and transition metal species. With these ylidones acting as soluble allotropes of silicon and germanium, they could also serve as reagents for unusual transformations - for instance as silicon or germanium atom transfer agents. Moreover, the strategy of synthesising silylones and germylones may also extend to other single, zero-valent main-group elements such as tin, lead, and even with group 2, 12, 13, and 15 elements. Beyond potential future applications, the unique bonding situation in these ylidones - where a central zerovalent $\mathrm{Si}$ or Ge atom is bound to neutral donating ligands expands the field of main group chemistry, by demonstrating a new way in which very unusual oxidation states can be trapped and utilised.

\section{Conflicts of interest}

There are no conflicts to declare.

\section{Acknowledgements}

We thank the Deutsche Forschungsgemeinschaft (Germany's Excellence Strategy-EXC 2008-390540038-UniSys-Cat and DR 226/21-1) for financial support.

\section{Notes and references}

1 R. Tonner, F. Öxler, B. Neumüller, W. Petz and G. Frenking, Angew. Chem., Int. Ed., 2006, 45, 8038-8042.

2 F. Ramirez, N. B. Desai, B. Hansen and N. McKelvie, J. Am. Chem. Soc., 1961, 83, 3539-3540.

3 G. E. Hardy, J. I. Zink, W. C. Kaska and J. C. Baldwin, J. Am. Chem. Soc., 1978, 100, 8001-8002.

4 G. Frenking and R. Tonner, Pure Appl. Chem., 2009, 81, 597-614.

5 R. Tonner, G. Heydenrych and G. Frenking, ChemPhysChem, 2008, 9, 1474-1481.

6 N. Takagi, T. Shimizu and G. Frenking, Chem. - Eur. J., 2009, 15, 8593-8604.

7 J. Turek, B. Braïda and F. De Proft, Chem. - Eur. J., 2017, 23, 14604-14613.

8 A. J. Arduengo III, R. L. Harlow and M. Kline, J. Am. Chem. Soc., 1991, 113, 361-363.

9 R. Tonner and G. Frenking, Angew. Chem., Int. Ed., 2007, 46, 8695-8698.
10 C. A. Dyker, V. Lavallo, B. Donnadieu and G. Bertrand, Angew. Chem., Int. Ed., 2008, 47, 3206-3209.

11 S. Ishida, T. Iwamoto, C. Kabuto and M. Kira, Nature, 2003, 421, 725-727.

12 M. Kira, T. Iwamoto, S. Ishida, H. Masuda, T. Abe and C. Kabuto, J. Am. Chem. Soc., 2009, 131, 17135-17144.

13 T. Veszprémi, K. Petrov and C. T. Nguyen, Organometallics, 2006, 25, 1480-1484.

14 M. Kosa, M. Karni and Y. Apeloig, J. Chem. Theory Comput., 2006, 2, 956-964.

15 N. Takagi, T. Shimizu and G. Frenking, Chem. - Eur. J., 2009, 15, 3448-3456.

16 T. Iwamoto, T. Abe, C. Kabuto and M. Kira, Chem. Commun., 2005, 5190-5192.

17 V. Lavallo, Y. Canac, C. Präsang, B. Donnadieu and G. Bertrand, Angew. Chem., Int. Ed., 2005, 44, 5705-5709.

18 K. C. Mondal, H. W. Roesky, M. C. Schwarzer, G. Frenking, B. Niepötter, H. Wolf, R. Herbst-Irmer and D. Stalke, Angew. Chem., Int. Ed., 2013, 52, 2963-2967.

19 Y. Xiong, S. Yao, S. Inoue, J. D. Epping and M. Driess, Angew. Chem., Int. Ed., 2013, 52, 7147-7150.

20 Y. Xiong, S. Yao, G. Tan, S. Inoue and M. Driess, J. Am. Chem. Soc., 2013, 135, 5004-5007.

21 Y. Li, K. C. Mondal, H. W. Roesky, H. Zhu, P. Stollberg, R. HerbstIrmer, D. Stalke and D. M. Andrada, J. Am. Chem. Soc., 2013, 135, 12422-12428.

22 T. Chu, L. Belding, A. Van Der Est, T. Dudding, I. Korobkov and G. I. Nikonov, Angew. Chem., Int. Ed., 2014, 53, 2711-2715.

23 M. T. Nguyen, D. Gusev, A. Dmitrienko, B. M. Gabidullin, D. Spasyuk, M. Pilkington and G. I. Nikonov, J. Am. Chem. Soc., 2020, 142, 5852-5861.

24 B. Su, R. Ganguly, Y. Li and R. Kinjo, Angew. Chem., Int. Ed., 2014, 53, 13106-13109.

25 S. Sarmah, A. K. Guha, A. K. Phukan, A. Kumar and S. R. Gadre, Dalton Trans., 2013, 42, 13200-13209.

26 T. Sugahara, T. Sasamori and N. Tokitoh, Angew. Chem., Int. Ed., 2017, 56, 9920-9923.

27 J. Keuter, A. Hepp, C. Mück-Lichtenfeld and F. Lips, Angew. Chem., Int. Ed., 2019, 58, 4395-4399.

28 Y. Wang, M. Karni, S. Yao, A. Kaushansky, Y. Apeloig and M. Driess, J. Am. Chem. Soc., 2019, 141, 12916-12927.

29 S. Yao, A. Kostenko, Y. Xiong, A. Ruzicka and M. Driess, J. Am. Chem. Soc., 2020, 142, 12608-12612.

30 Y. Wang, M. Karni, S. Yao, Y. Apeloig and M. Driess, J. Am. Chem. Soc., 2019, 141, 1655-1664.

31 S. Yao, A. Kostenko, Y. Xiong, C. Lorent, A. Ruzicka and M. Driess, Angew. Chem., Int. Ed., 2021, 60, 14864-14868.

32 M. Jadan, A. R. Chelyadins and V. Y. Yavid, Am. J. Appl. Sci., 2009, 6, 1242-1245.

33 F. J. Lovas, Astrophys. J., 1974, 193, 265-272.

34 J. L. Turner and A. Dalgarno, Astrophys. J., 1977, 213, 386-389.

35 C. A. Dyker and G. Bertrand, Science, 2008, 321, 1050-1051.

36 P. K. Majhi and T. Sasamori, Chem. - Eur. J., 2018, 24, 9441-9455.

37 S. Yao, Y. Xiong and M. Driess, Acc. Chem. Res., 2017, 50, 2026-2037.

38 G. Frenking, R. Tonner, S. Klein, N. Takagi, T. Shimizu, A. Krapp, K. K. Pandey and P. Parameswaran, Chem. Soc. Rev., 2014, 43, 5106-5139.

39 G. Frenking, M. Hermann, D. M. Andrada and N. Holzmann, Chem. Soc. Rev., 2016, 45, 1129-1144.

40 L. Zhao, M. Hermann, N. Holzmann and G. Frenking, Coord. Chem. Rev., 2017, 344, 163-204.

41 M. Kira, S. Ishida, T. Iwamoto and C. Kabuto, J. Am. Chem. Soc., 1999, 121, 9722-9723.

42 T. Iwamoto, H. Masuda, C. Kabuto and M. Kira, Organometallics, 2005, 24, 197-199.

43 N. Wiberg, H. W. Lerner, S. K. Vasisht, S. Wagner, K. Karaghiosoff, H. Nöth and W. Ponikwar, Eur. J. Inorg. Chem., 1999, 1211-1218.

44 K. C. Mondal, P. P. Samuel, M. Tretiakov, A. P. Singh, H. W. Roesky, A. C. Stückl, B. Niepötter, E. Carl, H. Wolf, R. Herbst-Irmer and D. Stalke, Inorg. Chem., 2013, 52, 4736-4743.

45 K. C. Mondal, H. W. Roesky, M. C. Schwarzer, G. Frenking, I. Tkach, H. Wolf, D. Kratzert, R. Herbst-Irmer, B. Niepötter and D. Stalke, Angew. Chem., Int. Ed., 2013, 52, 1801-1805.

46 R. S. Ghadwal, H. W. Roesky, S. Merkel, J. Henn and D. Stalke, Angew. Chem., Int. Ed., 2009, 48, 5683-5686. 
47 Y. Li, Y. C. Chan, B. X. Leong, Y. Li, E. Richards, I. Purushothaman, S. De, P. Parameswaran and C. W. So, Angew. Chem., Int. Ed., 2017, 56, 7573-7578.

48 S. C. Bart, E. Lobkovsky and P. J. Chirik, J. Am. Chem. Soc., 2004, 126, 13794-13807.

49 J. Flock, A. Suljanovic, A. Torvisco, W. Schoefberger, B. Gerke, R. Pöttgen, R. C. Fischer and M. Flock, Chem. - Eur. J., 2013, 19, 15504-15517.

50 T. Sasamori, T. Sugahara, T. Agou, K. Sugamata, J. D. Guo, S. Nagase and N. Tokitoh, Chem. Sci., 2015, 6, 5526-5530.

51 Y. Xiong, S. Yao, S. Inoue, E. Irran and M. Driess, Angew. Chem., Int. Ed., 2012, 51, 10074-10077.

52 Y. Xiong, S. Yao, S. Inoue, A. Berkefeld and M. Driess, Chem. Commun., 2012, 48, 12198-12200.

53 Y. Wang, Y. Xie, P. Wei, R. B. King, H. F. Schaefer, P. von, R. Schleyer and G. H. Robinson, Science, 2008, 321, 1069-1071.

54 A. Sidiropoulos, C. Jones, A. Stasch, S. Klein and G. Frenking, Angew. Chem., Int. Ed., 2009, 48, 9701-9704.

55 K. A. Kreisel, G. P. A. Yap and K. H. Theopold, Organometallics, 2006, 25, 4670-4679.

56 Y. Mizuhata, T. Sasamori and N. Tokitoh, Chem. Rev., 2009, 109, 3479-3511.

57 M. Asay, C. Jones and M. Driess, Chem. Rev., 2011, 111, 354-396.

58 S. Yao, Y. Xiong and M. Driess, Organometallics, 2011, 30, 1748-1767.

59 C. Shan, S. Yao and M. Driess, Chem. Soc. Rev., 2020, 49, 6733-6754.

60 C. W. So, H. W. Roesky, J. Magull and R. B. Oswald, Angew. Chem., Int. Ed., 2006, 45, 3948-3950.

61 Y.-L. Shan, W.-L. Yim and C.-W. So, Angew. Chem., Int. Ed., 2014, 53, 13155-13158.

62 B. Blom, M. Stoelzel and M. Driess, Chem. - Eur. J., 2013, 19, 40-62.

63 B. Blom, D. Gallego and M. Driess, Inorg. Chem. Front., 2014, 1, 134-148.

64 S. Raoufmoghaddam, Y. P. Zhou, Y. Wang and M. Driess, J. Organomet. Chem., 2017, 829, 2-10.

65 Y.-P. Zhou and M. Driess, Angew. Chem., Int. Ed., 2019, 58, $3715-3728$.

66 Z. Benedek and T. Szilvási, RSC Adv., 2015, 5, 5077-5086.

67 D. Gallego, S. Inoue, B. Blom and M. Driess, Organometallics, 2014, 33, 6885-6897.

68 Y. Wang, A. Kostenko, S. Yao and M. Driess, J. Am. Chem. Soc., 2017, 139, 13499-13506.

69 Y.-P. Zhou, S. Raoufmoghaddam, T. Szilvási and M. Driess, Angew. Chem., Int. Ed., 2016, 55, 12868-12872.

70 R. N. Grimes, Carboranes, Elsevier Science and Technology, Amsterdam, 2nd edn, 2011.

71 R. Núñez, M. Tarrés, A. Ferrer-Ugalde, F. F. De Biani and F. Teixidor, Chem. Rev., 2016, 116, 14307-14378.

72 A. C. Filippou, Y. N. Lebedev, O. Chernov, M. Straßmann and G. Schnakenburg, Angew. Chem., Int. Ed., 2013, 52, 6974-6978.

73 Y. Xiong, S. Yao, R. Müller, M. Kaupp and M. Driess, Angew. Chem., Int. Ed., 2015, 54, 10254-10257.

74 Y. Xiong, S. Yao, M. Karni, A. Kostenko, A. Burchert, Y. Apeloig and M. Driess, Chem. Sci., 2016, 7, 5462-5469.

75 B. Su, R. Ganguly, Y. Li and R. Kinjo, Chem. Commun., 2016, 52, 613-616.

76 A. Burchert, R. Müller, S. Yao, C. Schattenberg, Y. Xiong, M. Kaupp and M. Driess, Angew. Chem., Int. Ed., 2017, 56, 6298-6301.

77 A. V. Zabula, T. Pape, A. Hepp, F. M. Schappacher, U. C. Rodewald and R. Po, J. Am. Chem. Soc., 2008, 130, 5648-5649.

78 G. Thiele, Y. Franzke, F. Weigend and S. Dehnen, Angew. Chem., Int. Ed., 2015, 54, 11283-11288.
79 L. C. Siemes, J. Keuter, A. Hepp and F. Lips, Inorg. Chem., 2019, 58, 13142-13149.

80 C. Mohapatra, K. C. Mondal, P. P. Samuel, H. Keil, B. Niepötter, R. Herbst-Irmer, D. Stalke, S. Dutta, D. Koley and H. W. Roesky, Chem. - Eur. J., 2015, 21, 12572-12576.

81 K. Chandra Mondal, S. Roy, B. Dittrich, B. Maity, S. Dutta, D. Koley, S. K. Vasa, R. Linser, S. Dechert and H. W. Roesky, Chem. Sci., 2015, 6, 5230-5234.

82 Y. C. Chan, B. X. Leong, Y. Li, M. C. Yang, Y. Li, M. Der Su and C. W. So, Angew. Chem., Int. Ed., 2017, 56, 11565-11569.

83 R. Rodriguez, D. Gau, J. Saouli, A. Baceiredo, N. Saffon-Merceron, V. Branchadell and T. Kato, Angew. Chem., Int. Ed., 2017, 56, 3935-3939.

84 A. Burchert, S. Yao, R. Müller, C. Schattenberg, Y. Xiong, M. Kaupp and M. Driess, Angew. Chem., Int. Ed., 2017, 56, 1894-1897.

85 S. Roy, K. C. Mondal, L. Krause, P. Stollberg, R. Herbst-Irmer, D. Stalke, J. Meyer, A. C. Stückl, B. Maity, D. Koley, S. K. Vasa, S. Q. Xiang, R. Linser and H. W. Roesky, J. Am. Chem. Soc., 2014, 136, 16776-16779.

86 G. D. Frey, V. Lavallo, B. Donnadieu, W. W. Schoeller and G. Bertrand, Science, 2007, 316, 439-441.

87 A. Jana, C. Schulzke and H. W. Roesky, J. Am. Chem. Soc., 2009, 131, 4600-4601.

88 J. P. Moerdyk, G. A. Blake, D. T. Chase and C. W. Bielawski, J. Am. Chem. Soc., 2013, 135, 18798-18801.

89 A. V. Protchenko, K. H. Birjkumar, D. Dange, A. D. Schwarz, D. Vidovic, C. Jones, N. Kaltsoyannis, P. Mountford and S. Aldridge, J. Am. Chem. Soc., 2012, 134, 6500-6503.

90 A. V. Protchenko, A. D. Schwarz, M. P. Blake, C. Jones, N. Kaltsoyannis, P. Mountford and S. Aldridge, Angew. Chem., Int. Ed., 2013, 52, 568-571.

91 D. Wendel, A. Porzelt, F. A. D. Herz, D. Sarkar, C. Jandl, S. Inoue and B. Rieger, J. Am. Chem. Soc., 2017, 139, 8134-8137.

92 D. Wendel, T. Szilvási, C. Jandl, S. Inoue and B. Rieger, J. Am. Chem. Soc., 2017, 139, 9156-9159.

93 R. Rodriguez, D. Gau, T. Kato, N. Saffon-Merceron, A. De Cõzar, F. P. Cossío and A. Baceiredo, Angew. Chem., Int. Ed., 2011, 50, 10414-10416.

94 F. Lips, J. C. Fettinger, A. Mansikkamäki, H. M. Tuononen and P. P. Power, J. Am. Chem. Soc., 2014, 136, 634-637.

95 J. S. Han, T. Sasamori, Y. Mizuhata and N. Tokitoh, J. Am. Chem. Soc., 2010, 132, 2546-2547.

96 D. W. Stephan and G. Erker, Angew. Chem., Int. Ed., 2015, 54, 6400-6441.

97 D. W. Stephan, Science, 2016, 354, 1248.

98 A. Schäfer, M. Reißmann, A. Schäfer, M. Schmidtmann and T. Müller, Chem. - Eur. J., 2014, 20, 9381-9386.

99 Z. Mo, T. Szilvási, Y. P. Zhou, S. Yao and M. Driess, Angew. Chem., Int. Ed., 2017, 56, 3699-3702.

100 Z. Dong, Z. Li, X. Liu, C. Yan, N. Wei, M. Kira and T. Müller, Chem. - Asian J., 2017, 12, 1204-1207.

101 N. Del Rio, M. Lopez-Reyes, A. Baceiredo, N. Saffon-Merceron, D. Lutters, T. Müller and T. Kato, Angew. Chem., Int. Ed., 2017, 56, 1365-1370.

102 K. C. Mondal, P. P. Samuel, H. W. Roesky, R. R. Aysin, L. A. Leites, S. Neudeck, J. Lu, B. Dittrich, N. Holzmann, M. Hermann and G. Frenking, J. Am. Chem. Soc., 2014, 136, 8919-8922.

103 S. S. Sen, A. Jana, H. W. Roesky and C. Schulzke, Angew. Chem., Int. Ed., 2009, 48, 8536-8538.

104 S. Inoue and C. Eisenhut, J. Am. Chem. Soc., 2013, 135, 18315-18318. 